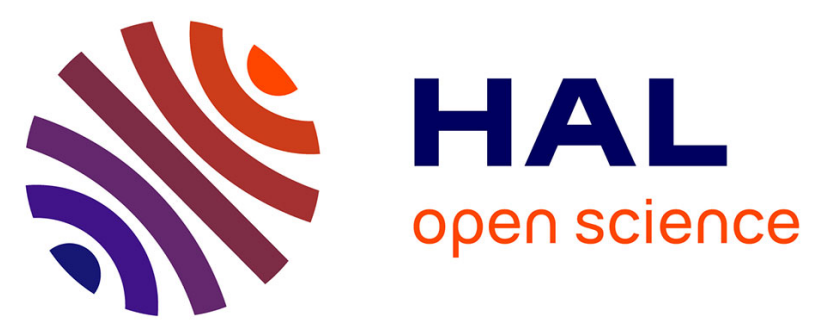

\title{
La France du Centre aux Pyrénées (Aquitaine, Centre, Limousin, Midi-Pyrénées, Poitou-Charentes)
}

José Gomez de Soto, Pierre-Yves Milcent, Jean-Philippe Baigl, Alexis

Gorgues, Pierre Moret, Olivier Nillesse, Christophe Sireix

\section{- To cite this version:}

José Gomez de Soto, Pierre-Yves Milcent, Jean-Philippe Baigl, Alexis Gorgues, Pierre Moret, et al.. La France du Centre aux Pyrénées (Aquitaine, Centre, Limousin, Midi-Pyrénées, Poitou-Charentes). Gallia - Archéologie de la France antique, 2003, Cultes et sanctuaires en France à l'âge du Fer, 60, pp.107-138. 10.3406/galia.2003.3145 . hal-01778055

\section{HAL Id: hal-01778055 \\ https://hal.science/hal-01778055}

Submitted on 8 Jan 2020

HAL is a multi-disciplinary open access archive for the deposit and dissemination of scientific research documents, whether they are published or not. The documents may come from teaching and research institutions in France or abroad, or from public or private research centers.
L'archive ouverte pluridisciplinaire HAL, est destinée au dépôt et à la diffusion de documents scientifiques de niveau recherche, publiés ou non, émanant des établissements d'enseignement et de recherche français ou étrangers, des laboratoires publics ou privés.

\section{(ㅇ)(1) $\$$}

Distributed under a Creative Commons Attribution - NonCommercial - NoDerivatives 44.0 


\title{
La France du Centre aux Pyrénées
}

\section{(Aquitaine, Centre, Limousin, Midi-Pyrénées, Poitou-Charentes)}

\author{
José Gomez de Soto et Pierre-Yves Milcent \\ avec la participation de Jean-Philippe BAIGL, Alexis Gorgues, \\ Pierre Moret, Olivier Nillesse, Christophe Sireix
}

\begin{abstract}
Mots-clés. Dépôts en milieu humide, fosses, puits, sanctuaires à dépôts d'armes, grottes, enclos fossoyés, stèles, statues.
Résumé. Le Sud-Ouest de la Gaule conserve, ce qui est rare, une tradition littéraire antique de dépôts sacrés, dans les étangs et dans le sanctuaire de Tolosa. De nombreux autres exemples de dépôts à caractère religieux sont connus par des découvertes anciennes, réinterprétées ici, ou des trouvailles récentes : objets jetés dans les milieux humides, enfouissements organisés dans des fosses ou des puits, dépôts codés de métaux précieux. Plusieurs sanctuaires à dépôts d'armes et d'outils sont connus en Centre-Ouest. Des restes humains en contexte d'habital, en silos, en région Centre, ou encore dans des cavités naturelles en Berry et Angoumois, échappent à un processus strictement funéraire. Dans les nécropoles-sanctuaires du Centre-Ouest, qui peuvent posséder des stèles de pierre, des puits et des fosses à sacrifice et/ou libation accompagnent des enclos fossoyés dont le caractère funéraire n'est pas toujours assuré, et des restes animaux $y$ indiquent des pratiques sacrificielles. Des statues traduisent des pratiques de culte des ancêtres.
\end{abstract}

Key-words. Deposit in watery context, pit, shaft, sanctuary with weapon deposit, cave, ditch-enclosure, standing stone, sculpture.

Abstract. In South-West France, ancient literary sources refer to treasures flung into the ponds and the sanctuary of Tolosa. A great number of sacred deposits are also known from past discoveries, being reinterpreted here, and recent finds: items thrown in watery places, organized deposits in pits or shafts, fine metalwork being buried. Several sanctuaries with weapon and tool deposits are known, particularly in Central-West Gaul. Human remains found in settlements, notably in storage-pits in the région Centre, or in natural caves in Berry and Angoumois, don't belong to a funerary process in the strict meaning sense. In funerary cult sites of the Centre-West having standing-stones, ditch-enclosures where funerary features are not always documented are accompanied with sacrificial and libation shafts and pits and faunal remains refer to sacrificial practices. Sculpture reveals practices relating to ancestral cults.

Schlagwörter. Gewässerdeponierungen, Gruben, Schächte, Heiligtümer mit Waffendeponierungen, Höhlen, Einfassungsgräbchen, Stelen, Statuen.

Zusammenfassung. Im Zusammenhang mit der Geschichte vom aurum tolosanum gibt es im Südwesten Galliens den seltenen Fall einer antiken Überlieferung zum Thema. Die Schriftquelle bezieht sich auf Deponierungen in den Seen von Tolosa. Altbekannte Funde, die hier neu interpretiert werden, und neue Entdeckungen liefern darüberhinaus allerlei Beispiele für Deponierungen mit religiösem Hintergrund. Darunter sind absichtlich in die Gewässer geworfene oder in Cruben und Schächten vergrabene Sachen ebenso wie planmäßig deponierte Edelmetallgegenstände. Besonders in der Region Centre-Ouest sind mehrere Heilgtümer mit Waffendeponierungen bekannt. Menschliche Überreste im Siedlungszusammenhang, wie sie in der Region Centre besonders in Silogruben oder im Berry und im Angoumois in natürlichen Vertiefungen anzutreffen sind, lassen sich mit regulären Bestattungen kaum in Einklang bringen.

In den Nekropolen mit Heiligtumscharakter der Region Centre-Ouest, die steinerne Stelen besitzen können, treten Schächte und Opfer/Libationsgruben zusammen mit Einfassungsgräbchen auf. Ihr Zusammenhang mit dem Crabbrauch ist allerdings nicht immer einwandfrei zu erweisen ist. Tierreste zeigen Opferpraktiken an. Statuen künden von der Praxis des Ahnenkults.

Übersetzt vom Stefan WIRTH 


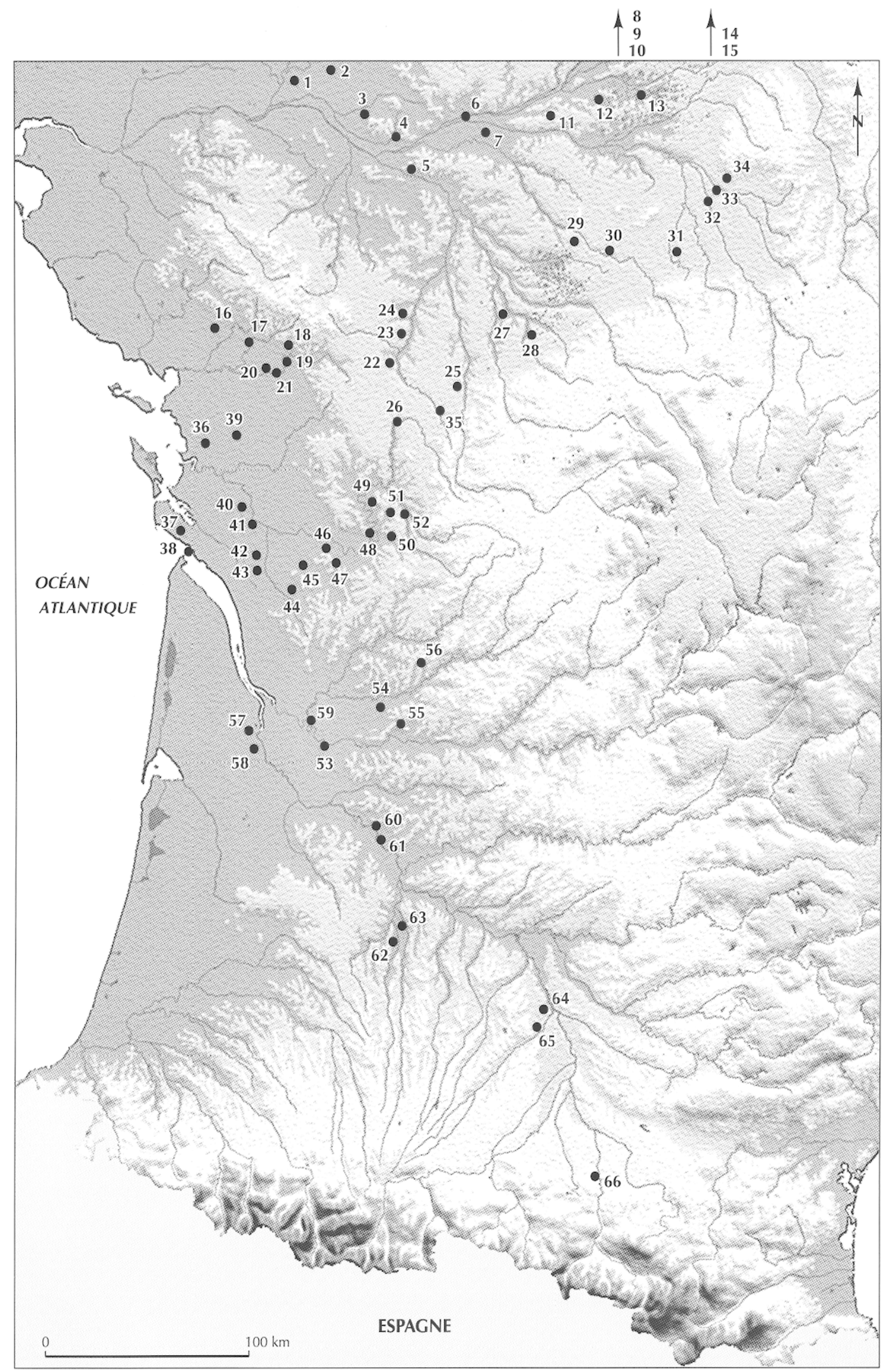

Fig. 62 - Carte de répartition des sites du Sud-Ouest de la France mentionnés dans le texte, voir tableau III (fond de carte P. Arcelin ; DAO G. Devilder, CNRS). 


\begin{tabular}{|c|c|c|c|c|c|}
\hline$N^{0}$ & Commune & Lieu-dit & Département & $N^{\circ}$ notice & Pagination \\
\hline 1 & Marcé & Ferme d'Hélouine & Maine-et-Loire & - & - \\
\hline 2 & Écouflant & Beuzon & Maine-et-Loire & - & - \\
\hline 3 & Saint-Laurent-de-Lin & Polleries & Indre-et-Loire & - & - \\
\hline 4 & Saint-Étienne-de-Chigny & Pont Clouet & Indre-et-Loire & - & - \\
\hline 5 & La Celle-Saint-Avant & Le Corps de Garde & Indre-et-I oire & - & - \\
\hline 6 & Amboise & Les Châtelliers & Indre-et-Loire & 1 & 122 \\
\hline 7 & Civray-de-Touraine & & Indre-et-Loire & - & - \\
\hline 8 & Montreuil & Fermaincourt & Eure-et-Loir (hors carte) & - & - \\
\hline 9 & Nottonville & La Pièce de la Cave & Eure-et-Loir (hors carte) & - & - \\
\hline 10 & Lumeau & & Eure-et-Loir (hors carte) & - & - \\
\hline 11 & Soings-en-Sologne & Ferme du Chastellier & Loir-et-Cher & 12 & 132 \\
\hline 12 & Saint-Viâtre & Pré Neunteau & Loir-et-Cher & - & - \\
\hline 13 & Souesmes & La Blinerie & Loir-et-Cher & - & - \\
\hline 14 & Pithiviers-le-Vieil & & Loiret (hors carte) & - & - \\
\hline 15 & Orléans & Lit de la Loire & Loiret (hors carte) & - & - \\
\hline 16 & Nalliers & L'Illéau-les-Vases & Vendée & - & - \\
\hline 17 & Fontenay-le-Comte & & Vendée & - & - \\
\hline 18 & Faye-l'Abbesse & Les Crânières & Deux-Sèvres & - & - \\
\hline 19 & Échiré & Le Chemin Chevaleret & Deux-Sèvres & 6 & 126 \\
\hline 20 & Coulon & Coteau de Montigné & Deux-Sèvres & - & - \\
\hline 21 & Niort & Le Pain Perdu & Deux-Sèvres & - & - \\
\hline 22 & Saint-Georges-lès-Baillargeaux & & Vienne & - & - \\
\hline 23 & Naintré & Vieux-Poitiers & Vienne & - & - \\
\hline 24 & Antran & La Croix Verte & Vienne & - & - \\
\hline \multirow{2}{*}{25} & Civaux & La Croix de Laps & Vienne & - & - \\
\hline & Valdivienne & Tombe au Cornemuseux & Vienne & - & - \\
\hline 26 & Savigné & Gros Guignon & Vienne & - & - \\
\hline 27 & Mérigny & La Roche Noire & Indre & 8 & 127 \\
\hline 28 & Saint-Marcel & Les Mersans & Indre & 11 & 132 \\
\hline 29 & Levroux & Les Arènes & Indre & 7 & $126-127$ \\
\hline 30 & Brion & Les Grandes Chapelles & Indre & - & - \\
\hline 31 & Châteaumeillant & Jardin Kasmarek & Cher & 4 & 125 \\
\hline 32 & Trouy & Givray, ZAC du Bois & Cher & - & - \\
\hline 33 & Bourges & Chemin de Gionne & Cher & 3 & $123-124$ \\
\hline 34 & Saint-Germain-du-Puy & Le Porteau & Cher & - & - \\
\hline 35 & Arnac-la-Poste & La Croix du Buis & Haute-Vienne & - & - \\
\hline 36 & Muron & Les Prés de Lise & Charente-Maritime & 9 & $127-128$ \\
\hline 37 & La Tremblade & Le Petit Maine Cabaud & Charente-Maritime & - & - \\
\hline 38 & Saint-Georges-de-Didonne & & Charente-Maritime & 10 & $128-132$ \\
\hline 39 & Surgères & & Charente-Maritime & - & - \\
\hline 40 & Port-d'Envaux & Les Nougérées & Charente-Maritime & - & - \\
\hline 41 & Courcoury & Le Terrier de la Fade & Charente-Maritime & 5 & $125-126$ \\
\hline 42 & Pons & Font Barbot & Charente-Maritime & - & - \\
\hline 43 & Saint-André-de-Lidon & & Charente-Maritime & - & - \\
\hline 44 & Chevanceaux & & Charente-Maritime & - & - \\
\hline 45 & Barbezieux-Saint-Hilaire & Les Petits Clairons & Charente & - & - \\
\hline 46 & Saint-Simon & Juac & Charente & - & - \\
\hline 47 & Roullet-Saint-Estèphe & Le Petit Berguille & Charente & - & - \\
\hline 48 & Angoulême & Marais de Grelet & Charente & - & - \\
\hline 49 & Villejoubert & Andone & Charente & - & - \\
\hline 50 & Touvre & Trou de la Coupe & Charente & - & - \\
\hline 51 & Agris & Grotte des Perrats & Charente & - & - \\
\hline 52 & Rivières & Ribérolles & Charente & - & - \\
\hline 53 & Port-Sainte-Foy-et-Ponchapt & & Dordogne & - & - \\
\hline 54 & Rouffignac-Saint-Cernin-de-Reilhac & Grotte de Rouffignac & Dordogne & - & - \\
\hline 55 & Coulounieix-Chamiers & La Curade & Dordogne & - & - \\
\hline 56 & Saint-Priest-de-Gimel & Puy-de-Lafont & Corrèze & - & - \\
\hline 57 & Bordeaux & Cité judiciaire & Gironde & 2 & 122 \\
\hline 58 & Cambes & & Gironde & - & - \\
\hline 59 & Tayac & & Gironde & - & - \\
\hline 60 & Agen & L'Ermitage & Lot-et-Garonne & - & - \\
\hline 61 & Boé & & Lot-et-Garonne & - & - \\
\hline 62 & Vic-Fezensac & & Gers & - & - \\
\hline 63 & Lectoure & & Gers & - & - \\
\hline 64 & Toulouse & & Haute-Garonne & 13 & $132-138$ \\
\hline 65 & Vieille-Toulouse & & Haute-Garonne & 13 & $132-138$ \\
\hline 66 & Pamiers & & Ariège & - & - \\
\hline
\end{tabular}

Tabl. III - Tableau des sites mentionnés sur la carte figure 62. 
La vaste aire concernée par cette contribution a connu une fortune archéologique assez disparate, et l'information se révèle assez inégale selon les régions '. Un peu partout, sauf à une date récente avcc la politiquc archéologique liée aux grands travaux, l'étude des sépultures s'est vue privilégiée. L'intérêt porté aux habitats s'est le plus souvent limité à quelques sites majeurs, comme Bourges, le Camp Allaric à Aslonnes, ou l'antique Tolosa.

Les informations concernant les pratiques cultuelles des âges du Fer ont souvent échappé lors des premières approches des sites, des témoignages discrets ont pu ne pas être reconnus. Dans de nombreux cas, la lecture funéraire s'est vue la seule privilégiée, systématiquement pour les ossements humains trouvés en milieu souterrain ou pour les puits d'Aquitaine, ceux du Toulousain en particulier. Lors de la fouille des sanctuaires gallo-romains, les indices d'une antériorité remontant à l'Indépendance ou n'ont pas été recherchés faute de fouilles en profondeur, ou n'ont pas été reconnus, comme à Faye-l'Abbesse.

En revanche, lieux de culte présumés, des enceintes quadrangulaires se sont révélées être des établissements d'habitat rural, tels ceux de Montrollet en Charente ou de La Cabane Rouge à Muron. Ce qui n'exclut pas que des pratiques cultuelles collectives ou privées s'y soient déroulées, mais leurs traces n'ont pas été reconnues de façon indiscutable.

Le nouvel examen de découvertes anciennes, les trouvailles et fouilles réalisées depuis un quart de siècle environ permettent toutefois d'établir un bilan relativement fourni (fig. 62 et tabl. III).

\section{LES SOURCES LITTÉRAIRES ANTIQUES ET LE SANCTUAIRE DES TECTOSAGES À TOLOSA}

Les sources antiques restent silencieuses pour les régions considérées, sauf en ce qui concerne le locus consecratus de la cité des Carnutes (César, B. G., VI, 13), non lucaulisé à ce jour (Ferdièrc, 1989), et le sanctuaire des Tectosages à Tolosa.

La description par Poseidonios du trésor et du sanctuaire des Tolosates vers 106 avant J.-C., transmise par Strabon (Géographie, IV, 1, 13), a été récemment étudiée (Moret, 2001). Une partie du trésor - constitué « d'or et d'argent bruts " - était déposée au fond d'étangs ou de marécages (le grec limnè peut désigner toute sorte d'eau stagnante), l'autre dans les enclos sacrés (sèkoi) d'un

1. Les auteurs remercient pour lcurs informations inédites $C$. Soyer, P. Mornais, T. Lejars, J.-C. Arramond, L. Fournier, D. L.croy et A. Luberne. sanctuaire (hiéron). Ce dernier était situé " dans Tolosa", c'est-à-dire probablement dans l'agglomération, à la différence des étangs pour lesquels aucun repère topographique n'est fourni, mais qui, d'après la structure de la phrase, se trouvaient à l'extérieur de la ville. Il faut donc bien distinguer ces deux pôles de la vie religieuse des Tolosates : une étendue d'eau morte laissée à l'état naturel en périphérie et des structures bâties dans l'agglomération. On peut se faire une idée approximative de ces dernières à partir de la fouille d'un petit sanctuaire de la première moitié du I ${ }^{\mathrm{er}} \mathbf{s}$. avant J.-C., mis au jour en 1970 à Vieille-Toulouse (Vidal, 2001a et infra notice 13, p. 132-138). Il s'agit d'une aire carrée de 4,90 m de côté, délimitée par un fossé ; à l'intérieur se faisaient face une banquette et un autel excavé rectangulaire dans lequel fut trouvée une statuette anthropomorphe de facture fruste.

Quant aux étangs, il faut sans doute les rechercher à proximité de la grande agglomération des $\mathrm{II}^{\mathrm{e}}$ et $\mathrm{I}^{\mathrm{cr}} \mathrm{s}$. qui est située en bord de Garonne dans le quartier Saint-Roch, au sud de Toulouse, et que nous connaissons grâce aux centaines de puits qui ont été découverts dans ce secteur, sur une superficie d'au moins 40 ha. D'importantes étendues d'eaux stagnantes existaient encore au XVII' s. au nord de ce secteur d'habitat, dans la dépression du Sauzat et dans le quartier du Busca (fig. 63) (Moret, 2001, p. 21). La conjonction remarquable d'une vaste agglomération et d'une zone marécageısse, à proximité d'un gué de la Garonne, invite à situer en ces lieux la capitale des Tectosages, telle que l'évoque Poseidonios.

\section{LES SANCTUAIRES DE PLEIN AIR À DÉPÔTS D'ARMES}

Les sanctuaires à dépôts d'armes sont connus en nombre déjà appréciable en Gaule de l'Ouest, de l'Armorique (Saint-Jean-Trolimon) au Centre-Ouest (Gomez de Soto, Lejars, 1991 ; Lejars, 1991). Non reconnus au XIX'c s. lors des fouilles des établissements gallo-romains qui leur succédèrent, on citera ceux de Nalliers et de Faye-l'Abbesse. Les matériaux conservés, récemment identifiés comme celtiques, ont fait l'objet d'études qui montrent la mise en place de ces lieux de culte au III's. avant J.-C. (Gendron, Gomez de Soto, 1986 ; Lejars, 1989).

Deux autres sanctuaires ont été identifiés récemment par des indices près de Vieux- Poitiers à Naintré et aux Prés de Lise à Muron, où une fouille partielle a été réalisée (Gomez de Soto, 1989, 1991 ; Gomez de Soto, Lejars, 1991 et infra notice 9, p. 127-128). L'aire interne de ce sanctuaire, aux limites mal définies, a révélé une fosse contenant faune (dont un crâne de cheval), amphores, céramique, 


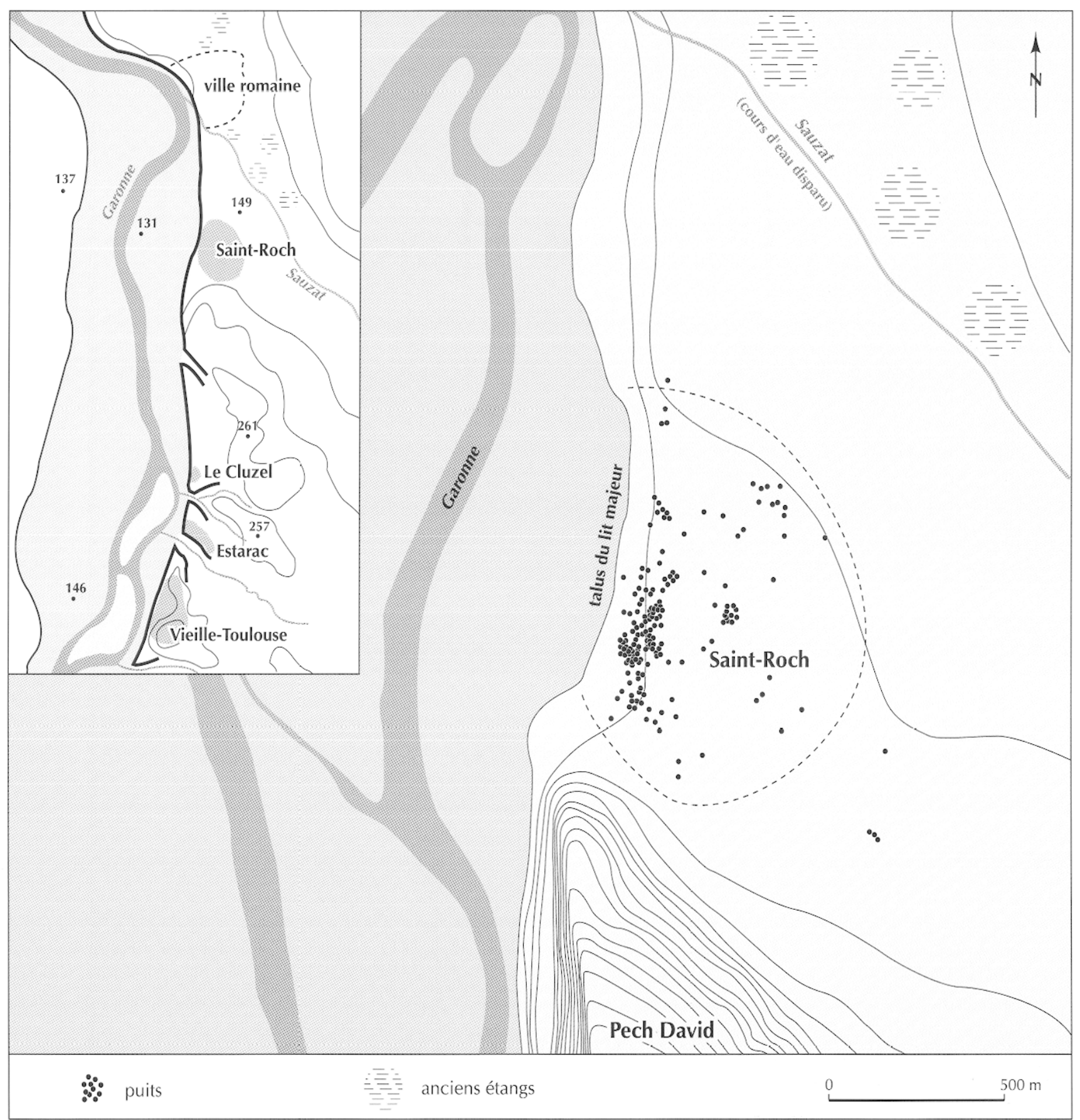

Fig. 63 - Le site de Tolosa. Emplacement de l'agglomération du quartier Saint-Roch et des étangs. En vignette : les différents sites de l'âge du Fer (DAO P. Moret, CNRS).

armes et des fragments d'un chaudron en bronze (fig. 71), mise en relation avec des pratiques de banquet (Poux, 2000a et $b$ ). Une des originalités de ce sanctuaire est la relative abondance des outils. Quelques armes du IVe s. permettent un rapprochement avec le sanctuaire de Saint-JeanTrolimon (Finistère), et posent de la même façon que ce dernier le problème de l'apparition des sanctuaires à dépôts d'armes dès cette époque en Occident, c'est-à-dire avant la date généralement admise, le III ${ }^{e} s$.

À Muron, Nalliers et Faye-l'Abbesse, un établissement gallo-romain fit suite au sanctuaire laténien. Malgré la toponymie celtique de certains lieux, les autres sanctuaires 
gallo-romains du Poitou-Charentes, comme, en Charente, ceux des Bouchauds à Saint-Cybardeaux ou de Chassenon, n'ont pas à cette date révélé de vestiges antérieurs à la conquête ${ }^{2}$. Au Pain Perdu à Niort, il est en revanche probable qu'un lieu de culte laténien précéda l'établissement gallo-romain : un important dépôt d'éléments du IV ${ }^{\mathrm{e}} \mathrm{s}$. avant J.-C. constitué, entre autres, d'une anse de chaudron à attache décorée d'un rinceau de style végétal continu et de coupelles en feuille de bronze ornées au repoussé en apporterait la preuve (Gomez de Soto, 1986).

La région Centre livre depuis peu des vestiges semblables: une portion d'un sol jonché d'os animaux (essentiellement des demi-crânes de porcs) et de quelques fragments d'armes de La Tène D2 a été dégagée dans la rue de La Nation à Bourges (Ruffier, 1990 et infra notice 3, p. 123-124) ; à Saumeray (Eure-et-Loir), deux enclos, l'un carré, l'autre circulaire, fournissent de l'armement de La Tène C2. Deux sites pourraient appartenir à la même catégorie d'établissements, mais cette attribution demeure incertaine en raison du caractère limité de la fouille (Pithiviers) ou de l'absence d'observations précises (Montreuil) : à Pithiviers-le-Vieil, un enclos quadrangulaire avec fossés comblés à La Tène $\mathrm{D}$ (présence de faune, céramiques et amphores), proche du sanctuaire gallo-romain de La Grande Raye (Cribellier, 1994) ; à Montreuil, un groupe de céramiques de La Tène $\mathrm{B}$ ou $\mathrm{Cl}$ associé à des pointes et talons de lances (Villes, 1985, p. 55).

\section{LES SANCTUAIRES EN GROTTE ET AUTRES MILIEUX SOUTERRAINS NATURELS}

Le statut des trouvailles des âges du Fer dans les grottes n'est pas toujours clair, en général faute d'observations précises ou de fouilles.

Seule la grotte des Perrats à Agris a fait l'objet d'une fouille sur une grande surface (Gomez de Soto, 1996). Le site fut fréquentè du $\mathrm{IV}^{\mathrm{e}} \mathrm{s}$. au $\mathrm{II}^{\mathrm{e}} \mathrm{s}$. avant J.-C.

$\mathrm{Au} I \mathrm{IV}^{\mathrm{c}} \mathrm{s}$. remonte le célèbre casque d'apparat, probablement enfoui dans une fosse au centre de la salle principale. Il apparaît comme une offrande aux entités chthoniennes, ce que corroborerait l'image du serpent cornu que porte la paragnathide. Il pourrait constituer le dépôt de fondation du sanctuaire. Son démontage, l'enfoncement affectant son timbre, la fracturation de ses garnitures externes peuvent

2. Les monnaies de l'Indépendance retrouvées sous un des temples des Bouchauds à Saint-Cybardeaux ne peuvent être dissociées (circulation résiduelle) des autres rêtrouvées de concert, espèces coltiques tardives des aristocrates romanisés et augustéennes. apparaître, au même titre que la déformation du casque d'Amfreville, un prémisse de la destruction des armes dans les sanctuaires de plein air. L'introduction des fragments des pièces externes à l'intérieur du timbre préalablement à l'enfouissement évoque les conditions du dépôt du sanglierenseigne de Soulac-sur-Mer (Moreau et al., 1990).

La faible quantité des artefacts de La Tène ancienne contraste avec l'abondance de ceux qui sont plus récents. Les matériaux de La Tène moyenne et finale comportent une quantité importante de céramique et des objets en métal souvent brisés et incomplets, essentiellement des outils. Les restes de faune ne sont abondants que dans la zone d'entrée. L'absence d'habitat avéré extérieur montre que la cavité restait très isolée en pleine nature, le maintien d'une tradition cultuelle peut alors être envisagé. La grotte serait devenue un petit sanctuaire rural analogue à ceux de l'âge du Fer de Gaule du Sud (Arcelin et al., 1992, p. 185). La fréquentation cultuelle de la grotte se poursuivra encore pendant le Haut-Empire romain (Gomez. de Soto, 1996, p. 107).

Des restes humains remontant aux âges du Fer présents dans un certain nombre de grottes doivent retenir l'attention, en particulier ceux du Trou de la Coupe à Touvre et de la zone du puits de Rouffignac-Saint-Cernin-de-Reilhac (Barrière, 1974, 2, p. 190 sqq.), qui ont livré des restes humains datant de La Tène finale. Des ossements de Touvre portent des traces d'intervention humaine et sont accompagnés de restes de faune, dont de suidés et de chevaux. À Rouffignac, dans l'environnement immédiat des restes, se trouvait un petit dépôt de monnaies d'argent et menus objets.

On est amené à douter, dans certains cas tout au moins, du caractère réellement funéraire de la présence des restes humains en milieu souterrain en Gaule de l'Ouest pendant les âges du Fer, époque où l'utilisation sépulcrale des grottes a généralement disparu ailleurs. Diverses trouvailles en France comme ailleurs en Europe éclairent cette question. Le cas de la grotte de Býčí Skála en Moravie est bien connu. On évoquera encore les grottes du Trou de l'Ambre à Éprave en Belgique (Mariën, 1970) et du Creux Beurnichot à Chenôves en Saône-et-Loire (Guillard, 1934-1935 ; Fischer, 1982), dans lesquelles furent également découverts des squelettes humains (les ossements du Trou de l'Ambre portaient de nombreuses traces de coups, on l'ignore pour ceux du Creux Beurnichot) et des objets divers, dont un dépôt monétaire à Chenôves. On a voulu reconnaître dans ces défunts des victimes de massacres. Plus vraisemblablement s'agit-il de témoignages de pratiques de sacrifices et d'offrandes en direction des puissances du monde chthonien. Le dépôt de monnaies de Chenôves aurait dans ce cas une signification parallèle avec celle des " trésors " 


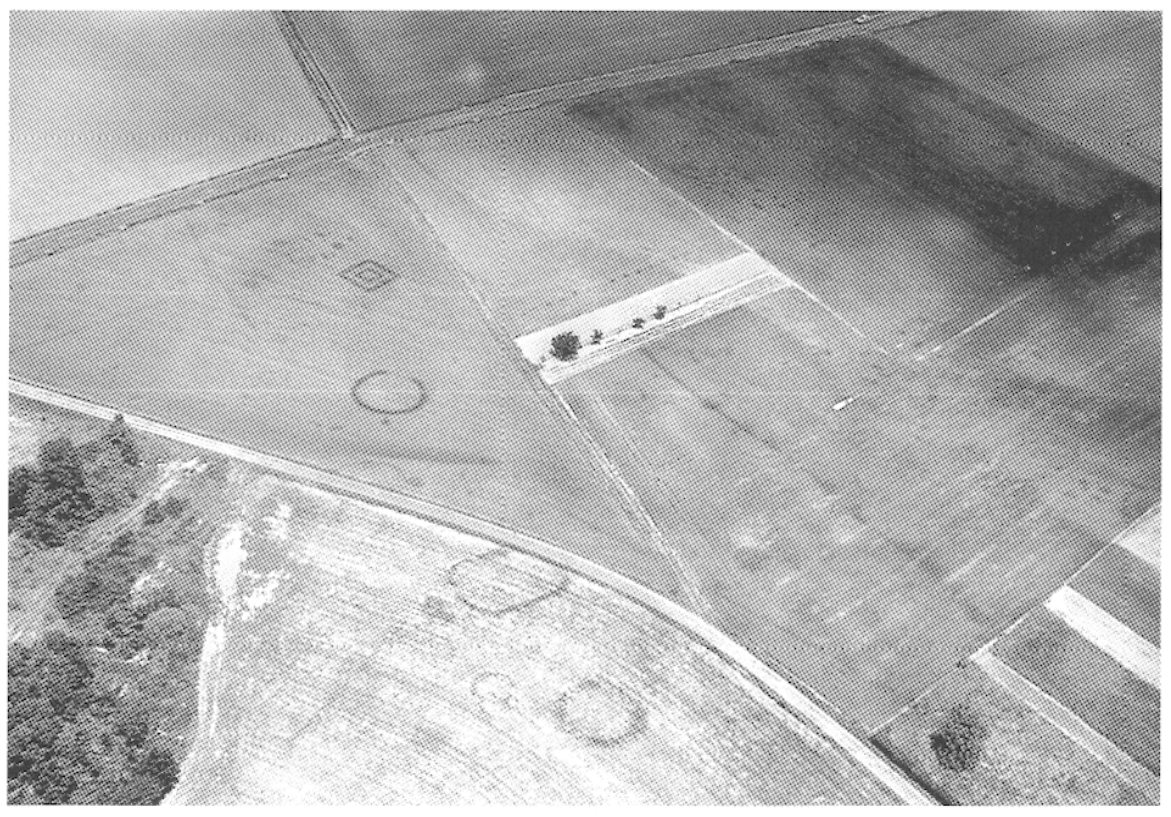

Fig. 64 - Rivières (Charente). Nécropolesanctuaire de Ribérolles (photo (C) J. Dassié). d'or celtiques déposés en des lieux hautement significatifs, en particuliers humides, qui relèvent des mêmes puissances. Les restes humains du Trou de la Coupe annoncent ceux de certains puits gallo-romains du Centre-Ouest, tels ceux de Nalliers ou de Saintes, dans lesquels des pratiques strictement codées d'offrandes ont été, en parallèle, mises en évidence.

\section{LES NÉCROPOLES-SANCTUAIRES ET LES PRATIQUES CULTUELLES EN MILIEU FUNÉRAIRE}

On doit à la prospection aérienne la découverte en Centre-Ouest de nombreux ensembles de monuments à fossés circulaires, quadrangulaires, en fer à cheval ou de formes curvilignes diverses. Les premiers enclos circulaires remontent au Campaniforme. Les formes quadrangulaires allongées apparaissent pendant le Bronze final, les plans carrés au Hallstatt D. De rares ensembles ont été très largement ou intégralement fouillés, dans la Vienne à Civaux et Valdivienne (Mataro i Pladelasala, 1988 ; Pautreau et al., 1992, 2000) et à Antran (Pautreau, 1985), en Charente à Rivières (Gomez de Soto, 1997, 1998) (fig. 64) et à RoulletSaint-Estèphe (Boguszewski et al., 2001), en CharenteMaritime à Saint-Georges-de-Didonne (Baigl et al., 1999 et infra notice 10, p. 128-132), ainsi qu'un certain nombre d'autres enclos en dehors de ces sites.

Le caractère uniquement funéraire de ces enclos est mis en question par la rareté des sépultures et, plus générale- ment, des restes humains, le plus souvent absents ou dans certains très rares cas réduits à quelques débris brûlés (enclos I et IV de Rivières; la Tombe au Cornemuseux à Valdivienne). L'hypothèse de la destruction de tombes déposées à même le sol sous la protection de tertres modestes détruits par les labours est certainement rcccvable, mais il serait imprudent de l'appliquer systématiquement. Quelques tombes situées à l'extérieur des enclos sont attestées, à Antran par exemple.

Nombre de monuments affichent des témoignages de pratiques ritualisées :

- dépôts de céramique présentant l'aspect de dépôts de fondation, à Antran (Pautreau et al., 1990, p. 259), Rivières et Courcoury (Gomez de Soto, 2002 et infra notice 5, p. 125-126) ;

- dépôts de restes d'animaux participant aux pratiques sacrificielles dans les sanctuaires, ou à forte connotation symbolique et/ou psychopompe, en particulier chevaux (crâne à Courcoury au Hallstatt D1, vestiges sur divers sites saintongeais du Hallstatt $\mathrm{C}$ à La Tène B) ou bovidés (dépôt de mandibules à Saint-Georges-de-Didonne au Hallstatt D, rappelant celui d'un fossé laténien d'Yverdon-les-Bains en Suisse, voir Brunetti, 2001), cerfs (paires de bois à RoulletSaint-Estèphe au Hallstatt D), chien (à Roullet-SaintEstèphe et Saint-Georges-de-Didonne), et même un important cortège de porcs, de moutons, de bœufs et de paires de chevaux et de chiens au Coteau de Montigné à Coulon vers 400 avant J.-C. (Pautreau, 1995, p. 55) ;

- stèles, encore rares : celle marquant l'entrée d'un enclos d'Antran a été érigée à la fin de l'âge du Bronze ou au 


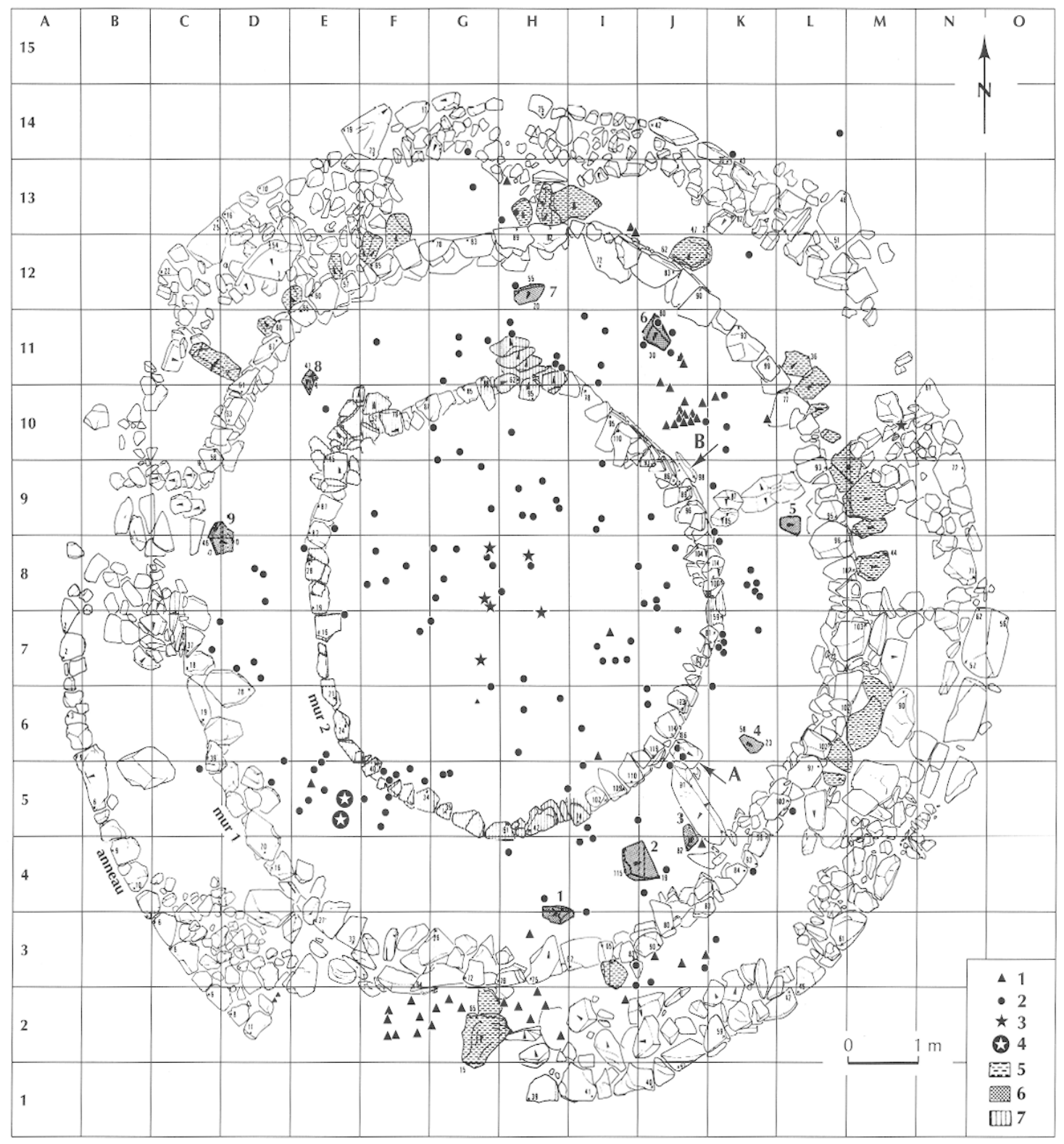

Fig. 65 - Saint-Priest-de-Gimel (Corrèze). Plan des architectures et répartition du mobilier du tumulus du Puy-de-Lafont: 1, tessons ; 2, fragments de galets de quartz; 3, fer; 4, bracelet en lignite; 5, contreforts; 6, pierres plantées ; 7, mur écroulé; $A, B$, orientations solsticiales (d'après Lintz, 1981, p. 10).

début de l'âge du Fer (Pautreau, 1985, p. 14). Celle de l'enclos IV-V du Coteau de Montigné à Coulon date de La Tène ancienne (Pautreau, 1995, p. 54). Deux stèles en cippes viennent des fossés d'enclos du Hallstatt $\mathbf{D}$ du Petit Berguille à Roullet-Saint-Estèphe, un fragment d'une autre provient, en contexte d'habitat celle-ci, du site de la Cité judiciaire à Bordeaux (Sireix, 1995 et infra notice 2, p. 122). Certains enclos de Roullet-Saint-Estèphe ont donné des blocs de taille notable, largement supérieure à celle des autres pierres comblant les fossés, qui, comme un bloc à aspect anthropomorphe naturel de l'enclos I de Courcoury, placé au IV $\mathrm{V}^{\mathrm{e}} \mathrm{s}$. (Gomez de Soto, 2002), paraissent pouvoir être considérés comme des stèles ou des bétyles ;

- dépôts d'armes : à Courcoury, le dépôt d'une lame d'épée mutilée de La Tène $B$ et les fragments d'une écuelle marquent la reprise d'un fossé d'enclos funéraire du $\mathrm{VI}^{\mathrm{e}} \mathbf{s}$. (Gomez de Soto, 2002), et traduisent la pérennité d'un lieu sacré encore illustrée au $\mathrm{II}^{\mathrm{e}} \mathrm{s}$. par deux "trésors" de 
monnaies et lingots d'or (Hiernard, 1999) ${ }^{3}$. Cette épée est à rapprocher des armes déposées en petit nombre dans des fossés d'enclos laténiens à vocation funéraire possible, mais non démontrée : tronçon de lame d'épée à Levroux (Colin, Buchsenschutz, 1984 et infra notice 7, p. 126-127); fourreau d'épée sectionné, umbo déformé incomplet et autres objets à Font Barbot, Pons (Gomez de Soto et al., 1993); umbo fragmenté à Valdivienne (Pautreau el al., 2000, p. 61). On évoquera encore le fer de lance tordu du fossé de l'enclos cultuel privé de l'établissement rural des Genâts à Fontenay-le-Comte (Poux et al., 2000), ou le fragment de bouterolle de fourreau d'un fossé de l'établissement rural du Chemin Chevaleret à Échiré (ibid. et infra notice 6, p. 126). Le caractère cérémoniel de ces dépôts a été présumé, hypothèse étayée par l'association avec des traces de consommation ritualisée du vin dans plusieurs cas (Poux et al., 2000) : c'est, en particulier, le cas à Échiré et à Pons.

Des structures particulières peuvent encore être associées à ces enclos :

- des fosses vides de tout dépôt funéraire, certaines contenant des coffrages de pierre ou des structures apparentées pouvant se trouver tant dans l'aire interne d'enclos qu'à l'extérieur, comme à Roullet-Saint-Estèphe, aux Nougérées, Port-d'Envaux (Coulaud el al., 1983, p. 6), à Cubord, Valdivienne (enclos 73, structure 122) (Mataro i Pladelasala, 1988, p. 24 ; Pautreau et al., 1992, p. 105) et Ribérolles, Rivières ;

- des puits ayant contenu des poteaux orientés, à Ribérolles. Ces puits du Ve $\mathrm{s}$. annoncent ceux des Viereckschanzen de Holzhausen (Bavière) et Tomerdingen (Bade). L'un d'entre eux a révélé des traces organiques animales ou humaines dont l'origine sacrificielle paraît vraisemblable. La dimension solaire du site de Ribérolles, de certaines de ses structures tout au moins, semble indiscutable si l'on prend en compte les orientations des poteaux des puits, et surtout l'enscmble constitué par l'enclos circulaire ouvert VII et ses deux structures associées (un puits et une fosse), qui fait figure de monument astronomique. La liaison d'un tel sanctuaire avec les cycles agraires, comme pour certains Viereckschanzen à puits à sacrifices (Duval, 1989), paraît probable.

Certains tumulus montrent des organisations internes en relation avec les positions du soleil. Le plus remarquable est celui du Puy-de-Lafont à Saint-Priest-de-Gimel où deux «fenêtres » d'un des murets matérialisaient les deux orientations solsticiales (Lintz, 1981, p. 10, 24) (fig. 65 et 66) ; dans d'autres cas, ce sont les positions d'entrées ou de pierres posées de chant qui par rapport au centre du tumulus

3. C'est un argument pour la lecture cultuelle des dépôts d'or celtique, monnaies (Fürger-Gunti, 1982) commc parures (en Gaule du SudOuest, examen critique : Gome\% de Soto, 1999 ; Hautenauve, 2001).

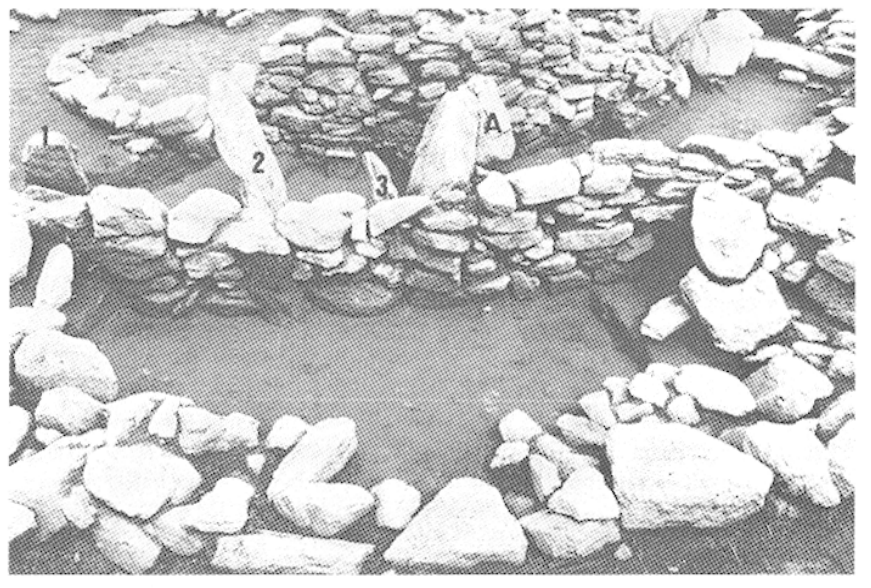

Fig. 66 - Saint-Priest-de-Gimel (Corrèze). Détail du quadrant sud-est du tumulus du Puy-de-Lafont: 1-3, pierres plantées; A, pierre de chant masquant une "fenêtre "à position solsticiale (photo G. Lintz, SRA Limousin).

marquent ces directions ou d'autres directions privilégiées (Beausolcil, Bretagnon, 1998 ; Beausoleil et al., 2000).

\section{LA QUESTION DES DÉPÔTS}

Dans la mesure où les structures spécifiques à des rituels autres que funéraires restent encore rares dans les régions concernées, nous nous attacherons essentiellement à la question des dépôts non funéraires. Nous ne pouvons éluder le fait que la dimension symbolique des dépôts n'est pas toujours évidente et qu'il est souvent impossible de faire le distinguo entre un trésor monétaire réuni en vue d'une récupération et l'offrande quasi définitive que constitue l'ensevelissement de monnaies à l'occasion d'une cérémonie de fondation. Conscients de cette difficulté, nous avons pris le parti de retenir un spectre de découvertes très large afin de ne pas restreindre les possibilités de lecture et d'interprétation ultérieures.

\section{LES DÉPÔTS D’OBJETS MÉTALLIQUES}

Constitués d'une matière qui présente une valeur intrinsèque importante, les objets en métal de moyenne et grande dimensions sont rarement abandonnés par hasard dans des sociétés rurales portées vers une économie autarcique, où le recyclage est une nécessité impérieuse. Ce sont de ce fait des matériaux privilégiés pour reconnaitre des gestes d'offrandes. Pour plus de commodité, nous distinguerons les dépôts en fonction de leur milieu d'abandon puis de leur composition. 


\section{UN CONTEXTE SPÉCIFIQUE : LES DÉPÔTS EN MILIEU HUMIDE}

Bien identifiés à l'âge du Bronze, les abandons volontaires en eaux librcs ou dormantes sont nettement plus rares à l'âge du Fer. Ils sont documentés dans le Toulousain par les textes relatifs aux sanctuaires de Tolosa (voir supra, p. 110). Plus que d'une réalité historique, ce décalage rend surtout compte de l'histoire et des disparités de la recherche puisque l'on sait que les objets en alliage cuivreux ont toujours été beaucoup plus soigneusement collectés que leurs homologues en fer lors de découvertes fortuites.

Les objets livrés aux eaux consistent essentiellement en parures (fibules, torques et bracelets) et armes au premier âge du Fer, en monnaies pour la fin du second âge du Fer. Quelques découvertes du premier âge du Fer sont remarquables dans la mesure où les objets impliqués dans ces pratiques sont d'origine lointaine (Milcent, 1998) : en Sologne, dans le Loir-et-Cher, les anneaux de cheville languedociens de Souesmes et les torques franconiens de Saint-Viâtre, à patine couleur rouille, étaient probablement ensevelis dans des contextes palustres aujourd'hui asséchés ; l'œnochoé étrusque du Pont Clouet à Saint-Étienne-deChigny paraît avoir été abandonnée en milieu humide au début du V $V^{e}$ s. avant J.-C.. ; à Bourges, une épée atlantique, un rasoir centre-italique et un poignard à antennes du BadeWurtemberg découverts dans les marais qui baignent le promontoire des agglomérations protohistoriques successives trahissent l'existence d'un lieu de déposition à caractère aristocratique dont le fonctionnement couvre la période du $\mathrm{IX}^{\mathrm{e}}$ au $\mathrm{VI}^{\mathrm{c}} \mathrm{s}$. avant J.-C.

Dans les fleuves et rivières, les trouvailles semblent souvent associées à des lieux de franchissement (ponts supposés et gués), ce qui peut traduire l'existence d'offrandes de passage. À Orléans, l'antique Genabum, les sables de la Loire au niveau de l'ancien pont de la ville ont livré un grand nombre d'objets, notamment un bracelet à tampons en fer, des pointes et talons de lance en fer, des fibules laténiennes en bronze (La Tène $\mathrm{C} 2$ pour la plus ancienne), des rouelles et surtout des centaines de monnaies celtiques, grecques et romaines républicaines et impériales en bronze, argent ou or (Desnoyers, 1876, 1898). Dans ce même lieu ont été collectés des objets métalliques du Bronze moyen et final, dont plusieurs rassemblés en un dépôt. La quantité et parfois la qualité des objets sont telles que l'hypothèse d'un lieu de culte à cet endroit mérite d'être formulée. Dans le Centre-Ouest et en Aquitaine, on connaît également des trouvailles métalliques des âges du Fer en milieu humide, encore peu nombreuses, dont des épées hallstattiennes près de Cambes et à Port-Sainte-Foy-et-Ponchapt, une épée à sphères à Juac (Saint-Simon), une épée à fourreau orné de dragons près de Surgères et une autre à poignée anthropoìde à Saint-André-de-Lidon, dont la lame portait des incrustations à caractère astral (Duval et al., 1986 ; Rapin, 1986).

En Angleterre (Flag Fen, Cambridgeshire, cf. Pryor dir., 1992) et en Allemagne septentrionale (Spandau près de Berlin, cf. Schwenzer, 1997), des sanctuaires aménagés en milieu humide fonctionnent dès l'âge du Bronze et il semble bien du reste que le site éponyme de La Tène en Suisse appartienne à cette catégorie de sites (Müller, 1992).

\section{LES DÉPÔTS D'OBJETS EN FER}

La rareté de ce type d'assemblages tient surtout à un problème d'identification. La sensibilisation croissante à ce genre de découvertes qui se réduisent fréquemment à quelques objets placés dans un trou de poteau devrait pallier rapidement ces lacunes (voir dépôt de la ferme d'Hélouine à Marcé, cf. Guillaumet, Nillesse, 2000).

Dans la région Centre, pour le premier âge du Fer, on relève à La Pièce de la Cave (Nottonville) une centaine de haches-simulacres réparties en deux dépôts et un troisième ensemble d'au moins 24 lingots bipyramidaux intacts (Lelong, 1991 ; Lelong, Aufaure, 1992) ; un dépôt restreint de haches fonctionnelles est documenté à Brion (Milcent, à paraître). À ce jour, nous ne connaissons pour le second âge du Fer qu'un dépôt, plus complexe que les précédents, composé d'une douzaine d'objets de fonctions diverses mutilés ou fragmentés sur l'établissement rural de La CelleSaint-Avant.

Nous avons évoqué ci-dessus, à propos des nécropolessanctuaires, les dépôts avec armes mutilées découverts hors des grands sanctuaires.

\section{LES TRÉSORS}

Les dépôts d'objets en métal précieux concernent principalement le second âge du Fer et consistent en torques d'or, ou bien en monnaies d'or ou d'argent. Le torque le plus ancien, daté de La Tène B1, est celui des Bruyères à Meungsur-Loire dans le Loiret (Jollois, 1836, p. 13, pl. VIII n ${ }^{\circ} 8$ ). Au contraire, celui de Civray-de-Touraine, de La Tène B2-Cl, brisé, était abandonné en milieu sec (Duval, Eluère, 1987). À Soings-en-Sologne, un troisième torque, à jonc massif et tampons creux, sans doute plus récent (La Tène C2 ou D1 ?), tordu, était associé à des monnaies d'or (Florance, 1926, p. 259-260). Ce type d'assemblage, un ou plusieurs torques mutilés et des monnaies d'or, est identifié dans pratiquement l'ensemble du domaine laténien (Fürger-Gunti, 1982), en contexte de sanctuaire à Ribemont-sur-Ancre (Somme) et assimilé à des trésors sacrés. 
Dans un registre proche, plusieurs " trésors " monétaires peuvent être reliés à des pratiques cultuelles : c'est le cas, au Terrier de la Fade à Courcoury en Saintonge, des deux trésors de monnaies et petits lingots d'or du II ${ }^{\mathrm{e}} \mathrm{s}$. (voir supra, p. 115), d'un dépôt de nature analogue à Chevanceaux, du dépôt d'un torque, de monnaies et de lingots à Tayac, du dépôt d'Amboise où huit potins déposés dans une céramique viennent sceller une fosse $\left(n^{\circ}\right.$ III) qui contenait des objets de fer remarquables (Peyrard, 1981 et infra notice 1, p. 122), ou encore, au sein de l'agglomération des Arènes à Levroux, des monnaies isolées ou rassemblées dans des fosses et trous de poteaux, qui constituent sans doute des dépôts de fondation (Buchsenschutz et al., 2000, p. 171). Des dépôts de monnaies des décennies postérieures à la conquête doivent encore être mentionnés, tels le dépôt de fondation d'un temple des Bouchauds à Saint-Cybardeaux (Charente) ou ceux déposés dans une fontaine à SaintSeurin-d'Uzet (Charente-Maritime) ou dans un coffre de pierre dans le sanctuaire du Pain Perdu à Niort (DeuxSèvres) (Hiernard, 1984).

\section{LES DÉPÔTS DE CÉRAMIQUES}

Rarement signalés en tant que tels, les abandons de céramiques qui s'intègrent ou qui font suite à un rituel demeurent difficiles à identifier. Nous ne connaissons que quelques exemples d'assemblages de vases entiers et souvent intacts. Les offrandes de vases lacunaires ou brisés restent du domaine de la spéculation dans la mesure où ces ensembles ne peuvent être, sauf condition particulière de dépôt et sous réserve d'une étude taphonomique poussée, distingués des assemblages domestiques. L'un a été identifié dans un habitat du début du premier âge du Fer à Saint-Germain-du-Puy. Les autres sont tardifs, il s'agit essentiellement des accumulations d'amphores intactes ou décolletées de certaines fosses quadrangulaires de l'oppidum de Châteaumeillant (Chevrot, Troadec, 1992, p. 192-197 et infra notice 4, p. 125). Toutefois, dans la mesure où ces fosses et leur contenu n'ont jamais fait l'objet d'études taphonomiques et fonctionnelles, on ne peut avancer l'hypothèse d'offrandes rituelles qu'avec réserves, d'autant que d'autres interprétations demeurent envisageables.

\section{LES DÉPÔTS MIXTES À OBJET(S) REMARQUABLE(S)}

Cette catégorie correspond aux assemblages intentionnels mêlant du matériel d'origine, de fonction et de matériau différents. C'est la plus répandue, mais souvent aussi la plus délicate à relier à la sphère des pratiques rituelles ou du culte en raison des ambiguités d'identification qui tiennent aux ressemblances avec le contenu des dépotoirs domestiques. La distinction entre les deux est pour partie subjective et tient principalement à l'identification de mobiliers remarquables par leur qualité ou leur rareté (et donc leur valeur supposée), leur fonction (armement et instruments associés aux pratiques sacrificielles et cérémonielles : couteaux de découpe, chaudrons, chenets, broches, crocs à viande, etc.), leur dépôt en série, ou bien encore par leur état (destruction volontaire ou au contraire mobiliers fragiles déposés intacts, etc.).

Les dépôts identifiés apparaissent tous dans des agglomérations, fortifiées ou non, de La Tène finale. Il convient probablement d'y voir l'effet du hasard dans la mesure où ces sites livrent une quantité importante de structures en creux et de matériel et, à ce titre, ont focalisé l'attention. Les exemples les plus remarquables proviennent des sites suivants :

- Amboise : fosse III de La Tène D2 avec un trésor de potins, des vases entiers, un chenet à protomés de palmipède en fer et un tronçon d'épée ou plutôt de currency bar; fosse IV avec cinq lève-loquets, sept potins, un as de Nîmes, une fibule et des vases entiers (Peyrard, 1981) ;

- Châteaumeillant: puits du Jardin Kasmareck avec un bouchon de pierres auxquelles était mêlé un buste en grès à base brisée, associé à de " nombreuses ramures de cerf " et à quelques vases augustéens (Hugoniot, Gourvest, 1961, p. 200, pl. XLIII) ;

- Levroux : fosse PH14 avec une statue du même type que la précédente ${ }^{4}$, également mutilée et accompagnée d'une ramure de cervidé, mais dans un contexte attribuable à La Tène Dlb (Krausz et al., 1989).

En Angoumois, on mentionnera la fosse 3038 de l'établissement rural et artisanal des Petits Clairons à Barbezieux-Saint-Hilaire, de La Tène $\mathrm{C}$, qui ne se distingue d'autres fosses du site que par son mobilier visiblement sélectionné : deux grands couteaux en fer, une allène en fer, un fragment d'objet en fer indéterminé (fourreau ou lame d'épée ?), un vase complet et la base complète d'un autre. Les tessons de ces deux récipients avaient pour certains subi l'action du feu, d'autres non. De plus, ces artefacts avaient été déposés en fond de fosse, laquelle était rebouchée de terre ne contenant que des matériaux détritiques d'ailleurs peu nombreux (Baigl, 2000a, p. 45 ; Gomez de Soto, 2000).

4. On connaît d’autres statues du second âge du Fer en région Centre, mais hors contexte (Coulon, 1990 ; Ménez et al., 1999 ; Milcent, 1999). 


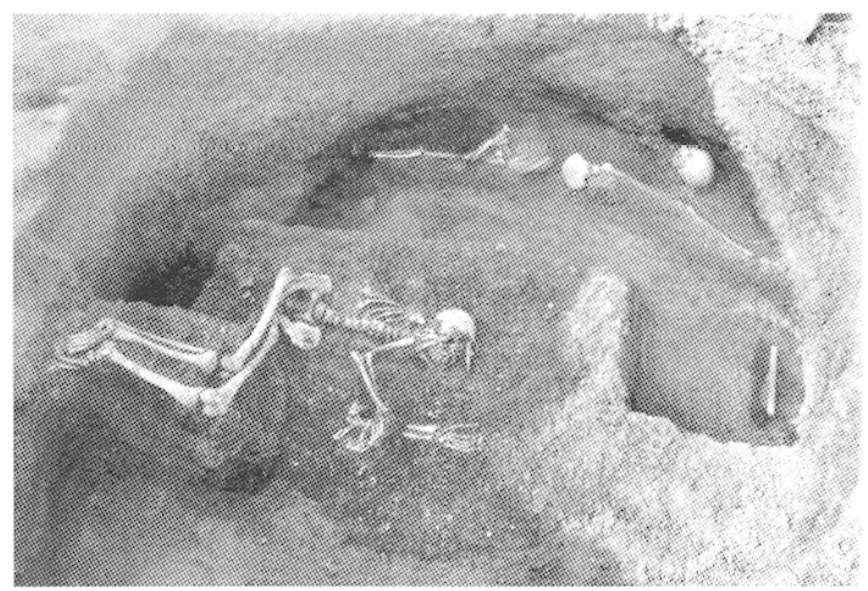

Fig. 67 - Bourges (Cher). Squelettes humains du silo F.4 du Chemin de Gionne (photo O. Buchsenschutz, CNRS).

\section{LES DÉPÔTS DE RESTES HUMAINS HORS DE CONTEXTES SPÉCIFIQUEMENT FUNÉRAIRES}

Il s'agit de considérer ici les dépôts de corps humains, entiers ou non, en dehors des espaces réservés à l'ensevelissement de ces dépouilles que sont les cimetières. Nous identifions trois catégories de lieux qui recueillent des restes hors les nécropoles : les habitats, les structures de stockage périphériques aux habitats et un type de lieu naturel à forte connotation symbolique, la grotte. Nombre de découvertes concernent les $\mathrm{V}^{\mathrm{c}}-\mathrm{IV}^{\mathrm{c}} \mathrm{s}$. avant J.-C. et le Berry, mais il semble bien que ce déséquilibre résulte pour partie de l'état de la recherche.

La signification de ces dépôts a fait l'objet d'hypothèses diverses et demeure discutée. Si les archéologues s'accordent pour considérer que les inhumations de périnataux en contexte d'habitat reflètent un traitement funéraire affaibli, voire nul, pour des sujets qui ne sont pas encore pleinement intégrés à la communauté sociale (Dedet, 1992, p. 263-267), il n'en va pas de même pour les enfants et les adultes. Pour ceux-ci, on a pu évoquer que leur dépôt en dehors des cimetières était assimilable à :

- une privation de sépulture (il faudrait dès lors parler d'inhumation de relégation et non de sépulture de relégation) qui serait l'expression d'une relégation sociale ou la conséquence d'une mort jugée mauvaise (Villes, 1986) ;

- des sacrifices humains (id., ibid.) ;

- des pratiques funéraires singulières dont certaines viseraient à la constitution de reliques ou, in fine, à « offrir " la dépouille à l'occasion de rituels propitiatoires, de fondation ou d'intercession, dans lesquels on ferait intervenir des ancêtres défunts, etc. (Delattre, 2000).
Sauf cas particuliers et récemment étudiés, les conditions d'observation, de fouille et de conservation des vestiges osseux offrent rarement la possibilité de trancher entre ces différentes hypothèses. De surcroît, la diversité des cas de figure est telle que chaque dépôt nécessiterait un examen anthropologique spécifique avant d'espérer pouvoir aborder le dossier de façon synthétique, période par période. Nous sommes bien loin du compte dans ce domaine pour les régions qui nous intéressent.

\section{DÉPÔTS EN SITE D'HABITAT}

Des restes humains erratiques sont signalés dans divers contextes domestiques. Les études des vestiges osseux issus des habitats, là où elles sont pratiquées plus systématiquement, laissent entendre que ces trouvailles sont assez banales. Plusieurs hypothèses peuvent rendre compte de cette situation, mais en l'absence d'une enquête anthropologique systématique aucune ne prime sur les autres. Pour toutes ces raisons, nous ne nous étendrons pas sur le sujet ici. En revanche, la mise au jour de membres ou de corps en connexion est plus rare et mérite examen. Les sites concernés se rapportent tous à la transition premier-second âges du Fer et à La Tène ancienne.

Les restes d'un nourrisson dans un remplissage de trou de poteau du faubourg artisanal de Saint-Martin des Champs à Bourges complètent l'observation d'inhumations d'immatures en contextes domestiques, notamment dans les agglomérations de la Gaule méridionale (Dedet et al., 1991). Une inhumation et un membre humains proviennent d'une tranchée de palissade de l'établissement du IV ${ }^{e} s$. avant J.-C. des Chassepins à Bourges (Buchsenschutz, Ralston dir., 2001). Il est intéressant de rapprocher ces éléments de découvertes du XIX ${ }^{\mathrm{e}} \mathrm{s}$. à Bourges : dans la zone des actuels établissements militaires, plusieurs corps humains portant des parures du Ve s. avant J.-C. ont été mis au jour dans des fosses polylobées et des fossés parallèles.

\section{DÉPôTS EN SILO OU FOSSE EN FORME DE SILO}

Plusieurs fosses, probables silos, contenant des corps humains plus ou moins complets sont identifiées. Le site le plus remarquable est celui du Chemin de Gionne à Bourges (fig. 67), avec une importante batterie de silos dont l'utilisation et le colmatage s'étalent sur une période relativement longue (fin $\mathrm{V}^{\mathrm{c}}$-III ${ }^{\mathrm{c}} \mathrm{s}$. avant J.-C.). Outre le nombre assez important de sujets ensevelis -7 répartis entre 5 structures l'intérêt du site réside dans la présence de mobiliers individuels (bracelets, fibule), de dépôts annexes ou d'accompagnement (crânes de chevaux, fragments d'armes, tessons, etc.), ainsi que dans les manipulations sur les corps : 
décollations, reprise d'un calvarium dans un silo après décollation et décharnement.

D'autres inhumations ou parties de corps humains sont recensées et demanderaient un examen détaillé : silos ou fosses cylindriques de la caserne des pompiers et des environs de la villa de Lazenay à Bourges, de Gidy dans le Loiret (Villes, 1982), de Lumeau en Eure-et-Loir (Calvo, 1975), de Saint-Laurent-de-Lin en Indre-et-Loire.

\section{DÉPÔTS EN GROTTE}

En région Centre, la grotte de La Roche Noire à Mérigny demeure isolée dans cette catégorie (Cordier, 1978 et infra notice 8, p. 127). Plusieurs cavités au sein du même réseau irrigué par un bras de l'Anglin ont été utilisées pour des dépôts d'os humains représentant au minimum quinzc adultes et sept enfants. Le cadre, bien sûr, mais aussi la faune et un matériel céramique abondant, où les vases de stockage sont bien représentés, font de ce site un gisement à caractère funéraire bien distinct des autres pour le $V^{\mathrm{e}} \mathrm{s}$. avant J.-C. Le réseau offre des points communs avec les cavités à offrandes du Centre-Ouest et d'Aquitaine, que nous avons traitées supra, ainsi qu'avec la grotte des Palabres à Boussac dans le Lot (Crubézy et al., 2000), mais en l'absence d'étude anthropologique il serait imprudent d'aller au-delà de ce constat.

\section{LA QUESTION DES PUITS CULTUELS}

La nécropole-sanctuaire de Ribérolles à Rivières nous a amenés à évoquer ci-dessus les puits cultuels à poteaux. Les puits sont un élément caractéristique de nombreux sites gaulois du Sud-Ouest, en particulier chez les Volques Tectosages et leurs voisins de l'Ouest et du Nord. À ce jour, plus de 500 puits des II $^{c}$ et $\mathrm{I}^{\mathrm{cr}} \mathrm{s}$. avant J.-C. ont été identifiés sur divers sites de Toulouse et de ses environs immédiats, ainsi qu'à Albi, Castres, Agen, Rodez, Lectoure, VicFezensac et Pamiers (synthèse récente: Vidal, 2001b, à compléter par Benquet et al., 2001 et Boudet, 1996).

Dès les premières fouilles, les puits des Tolosates furent considérés comme des tombes à incinération, et le site de Saint-Roch comme une nécropole (Joulin, 1912). Reprise par M. Labrousse (1968), puis, avec des nuances, par M. Vidal (1977 et $200 \mathrm{lb})$, cette interprétation a été récemment contestée, compte tenu du fait que les restes humains font défaut dans la majorité des puits et que, lorsqu'ils existent, ils se situent dans des couches de comblement hétérogènes, souvent assez haut dans le puits, et non dans un dćpôt organisć situć au fond du puits. $\hat{\Lambda}$ partir de ce constat, R. Boudet (1996) et J. Gomez de Soto (1994 et
2001) ont proposé d'interpréter les puits du Toulousain comme des puits rituels à offrandes, dans le cadre d'un culte chthonien. La notice 13 (voir infra, p. 132-138) présente les arguments qui militent, pour plusieurs puits de Toulouse et de Vieille-Toulouse, en faveur d'une autre fonction : celle de puits à eau, l'élément cultuel se limitant, le cas échéant, à une offrande déposée entre le creusement du puits et sa mise en service.

Parmi les puits des autres sites de Gaule du Sud-Ouest, les deux puits de L'Ermitage à Agen méritent une mention particulière (Boudet, 1996). Aucun reste humain n'y fut découvert, mais ils contenaient des dépôts organisés d'une grande richesse incluant œnochoés en bronze et casques, avec des organisations géométriques dans certains cas. Le puits 41 en contenait plusieurs à des hauteurs différentes (fig. 68). L'absence d'épée est à souligner, et rapproche ces puits de ceux du Toulousain qui n'en contiennent jamais, quand bien même casque ou lance sont présents.

Une fonction cultuelle semble donc bien l'explication à retenir pour les puits d'Agen qui furent comblés rapidement après le dépôt d'offrandes. La même interprétation s'applique à la fosse à char tardi-celtique de Boé (Boudet, 1996 ; Schönfelder et al., 2000), comme aux fosses d'époque gallo-romaine ancienne dépourvues de restes humains mais à riche dépôt (dont des armes) d'Antran (Pautreau dir., 1998) et à char de Saintes (Bouchette et al., 1998). Le caractère funéraire de ces structures présentant l'apparence de tombes a été contesté (Gomez de Soto, 1994).

Une analyse critique s'impose pour d'autres puits d'Aquitaine septentrionale, tels ceux de La Curade à Coulounieix-Chamiers (Chevillot et al., 1996), dont la fonction cultuelle reste à démontrer.

\section{LE BANQUET ET LE VIN}

Des lots importants d'amphores ont été retrouvés dans des conditions qui font présumer un usage particulier de leur contenu, dans le cadre de banquets à forte connotation sociale et/ou cultuelle. Le cadre funéraire stricto sensu ne doit pas nous retenir ici. Hors de ce cadre, en PoitouCharente, on citera l'établissement rural du Chemin Chevaleret à Échiré, le site à connotation funéraire de SaintGeorges-lès-Baillargeaux, le sanctuaire de Muron, déjà évoqué, ou encore le fossé à amphores des Marais de Grelet à Angoulême.

À une dizaine de kilomètres de Bourges, des dépôts d'amphores parfois décolletées et associés à de la faune, à des meules, ainsi qu'à un mobilier métallique (pièces de char ?) et céramique abondant de La Tène D2 ont été mis au jour dans les fossés d'un enclos quadrilatéral à la ZAC du 


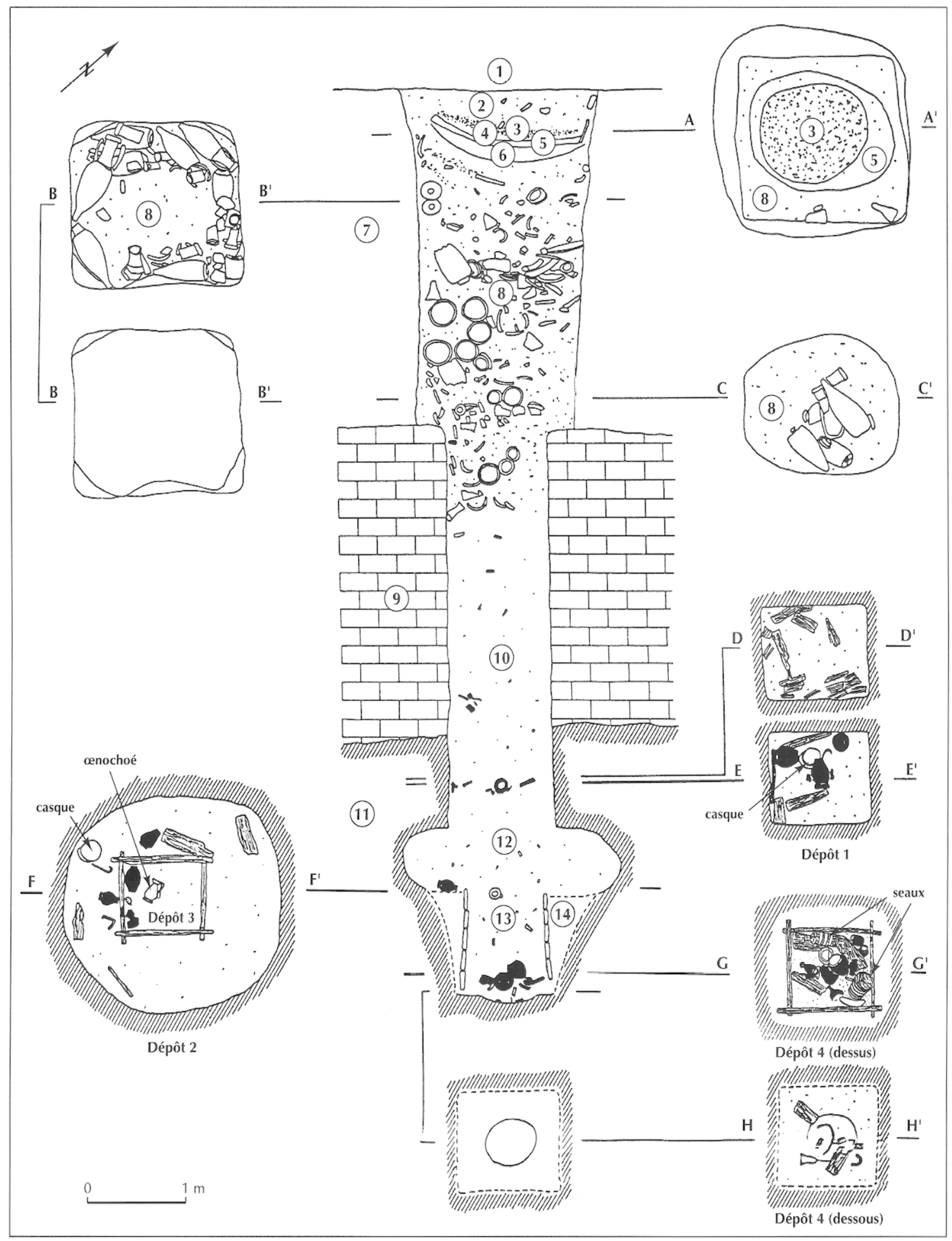

Fig. 68 - Agen (Lot-et-Garonne).

Coupe et relevés à différentes profondeurs du puits 41 de L'Ermitage (d'après Boudet, 1996, p. 82). 
Bois Givray, Trouy (Hascoët, Cribellier, 2001). Il pourrait s'agir des reliefs de l'un de ces grands festins celtiques rapportés dans les textes antiques (Perrin, 1999). D'autres vestiges du même ordre apparaissent sous les fana de l'oppidum des Mersans à Saint-Marcel.

L'enclos quadrangulaire de La Croix du Buis à Arnac-laPoste (fig. 69) a livré les restes de plus de 800 amphores Dressel 1A, et encore sa fouille n'est-elle pas exhaustive (Toledo i Mur, 1997-1998) ! À l'intérieur avait été érigé un bâtiment à trois pièces (bât. 2) s'ouvrant sur une galerie comparable aux hestiatoria du monde gréco-romain, bâtiments réservés aux banquets rituels (Poux, 2000a, p. 226). Des éléments sculptés originaux, têtes de bovidés en terre cuite, tête quadrifrons en pierre (Guillaumet, 19971998), inconnus sur lcs autrcs sitcs régionaux, confirmcnt lc caractère exceptionnel des lieux, abandonnés seulement vers 20 après J.-C.

\section{DES MARQUEURS \\ DE STATUT SACERDOTAL?}

Quelques rares tombes de l'élite contiennent des éléments que l'on peut considérer comme des marqueurs du rôle sacerdotal de leurs détenteurs.

La tombe à épée du VII ${ }^{\mathrm{c}}$ s. d'Andone à Villejoubert possédait, déposées en situation privilégiée, une hache en fer et une coupe carénée proche du modèle des phiales du type Colmar. Ces deux éléments ont été interprétés, à la lumière des rares tombes à hache du premier âge du Fer d'Europe, dont celle de Hochdorf (Krauße, 1996), le premier comme instrument du sacrifice, le second comme récipient pour libation (Debord et al., 2000).

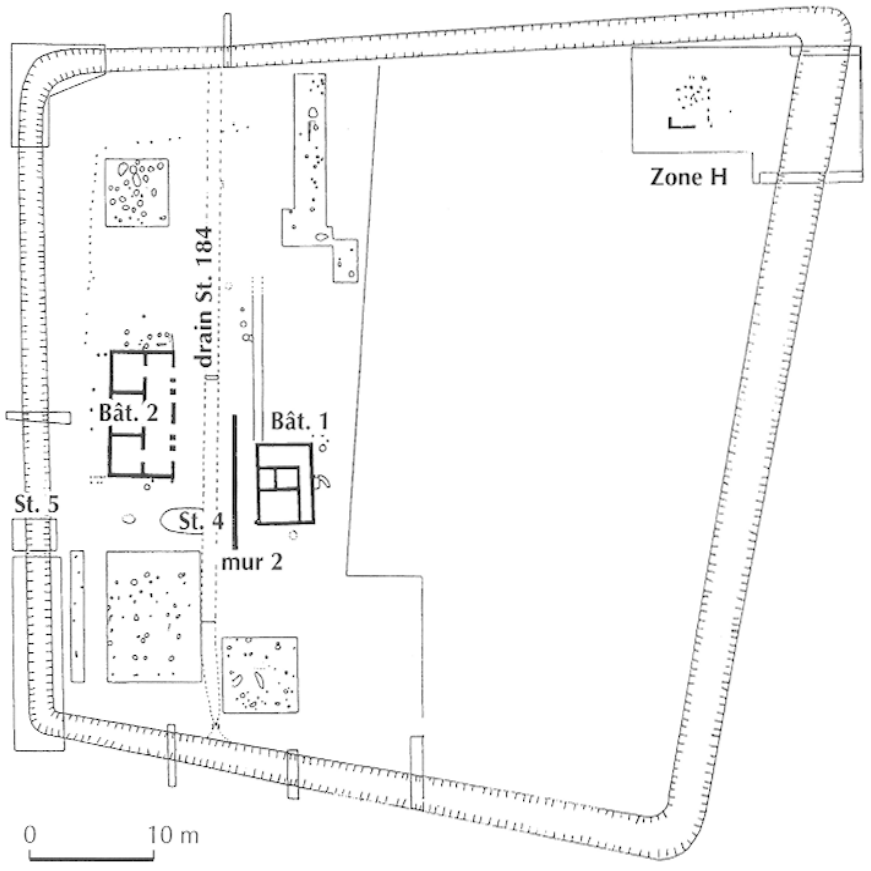

Fig. 69 - Arnac-la-Poste (Haute-Vienne).

Plan général de l'enclos de La Croix du Buis : le bâtiment 2 pourrait être une hestiatoria (d'après Toledo i Mur, 1997-1998).

Du tumulus du Gros Guignon à Savigné, daté de la fin $\mathrm{VI}^{\mathrm{c}}$-début $\mathrm{V}^{\mathrm{c}} \mathrm{s}$. avant J.-C., proviennent des fragments d'un simpulum (Gomez de Soto, Pautreau, 1988). On ne sait malheureusement pas si cet objet vient de la tombe à char ou de la sépulture primaire du tumulus. De tels instruments étaient utilisés au cours de banquets à forte charge symbolique cultuelle et sociale, probablement liés à la sphère du sacrifice. 


\section{NOTICES}

\section{NOTICE 1}

\section{AMBOISE (INDRE-ET-LOIRE)}

\section{Les Châtelumers}

En rive gauche de la Loire, l'oppidum des Châtelliers couvre une cinquantaine d'hectares et présente deux lignes de remparts. Les occupations connues datent surtout de La Tène D2 et du règne d'Auguste (Colin, 1998), mais des découvertes attestent une fréquentation ancienne du site (au Néolithique et à l'âge du Bronze). À proximité et au nord du centre de l'oppidum où se trouvent les substructions d'un temple gallo-romain, dans le quartier du VVF, ont été fouillées à $200 \mathrm{~m}$ l'une de l'autre deux fosses (III et IV) à dépôts symboliques. Au sud, à peu de distance, a été recueillie une statue de facture laténienne figurant un personnage assis en tailleur portant deux torques (Peyrard, 1981, 1982).

Dans le comblement épargné de la fosse III, en partie détruite, du matériel de La Tène D2 fut recueilli: au sommet un petit vase contenant huit potins à la tête diabolique des Turons, plus bas de la faune (porcins dominants, ovins, bovidés), plusieurs vases entiers "globuliformes", trois " coupelles ", une coupe entière, un morceau d'épée ou de lingot en forme d'épée, un chenet en fer intact à protomés de palmipèdes.

Le comblement de la fosse IV semble avoir été rapide. L'argile de colmatage du sommet présentait des traces d'action du feu. Là aussi fut identifié un dépôt symbolique, mais d'époque augustéenne: vases entiers, fragment de coupe campanienne, potins, as de Nîmes, fibule en alliage cuivreux, cinq lève-loquets en fer, vestiges de faune comparables à ceux de la fosse III.

Bibliographie : Peyrard, 1981, 1982 ; Colin, 1998.

P.Y. MILCENT

\section{NOTICE 2}

\section{BORDEAUX (GIRONDE)}

\section{LA Cité JudiciaIRE}

Le site de La Cité judiciaire à Bordeaux est un habitat de fond de vallée, à $700 \mathrm{~m}$ au nord-ouest des limites de l'habitat groupé contemporain connu à ce jour pour l'agglomération bordelaise (Sireix, 1995).
Une stèle, découverte au cours d'une opération de fouille préventive, se trouvait en réemploi dans un petit muret de pierres sèches du premier âge du Fer ou du début $\mathrm{du}$ second, contemporain d'un niveau de circulation reposant sur des limons de décantation du fond de la vallée du Peugne. Une datation par le ${ }^{14} \mathrm{C}$ indique une fréquentation entre 773 et 426 avant J.-C. (Ly-6132).

Fragmentée et incomplète, elle présente un manque dans sa partie supérieure. Ses surfaces sont altérées. Elle offre l'aspect d'un bloc parallélépipédique aux angles chanfreinés, et a visiblement été retaillée dans un bloc calcaire qui portait déjà des cupules (fig. 70). Sa hauteur actuelle est de $0,47 \mathrm{~m}$, son pied carré a $0,22 \mathrm{~m}$ de côté à la base, il est haut de $0,20 \mathrm{~m}$ à $0,22 \mathrm{~m}$, la largeur du chanfrein varie de $0,04 \mathrm{~m}$ à $0,06 \mathrm{~m}$.

La stèle est actuellement conservée au dépôt de fouilles du Service régional de l'archéologie d'Aquitaine à Pessac (Gironde).

Bibliographie : Sireix, 1995.

C. SIREIX

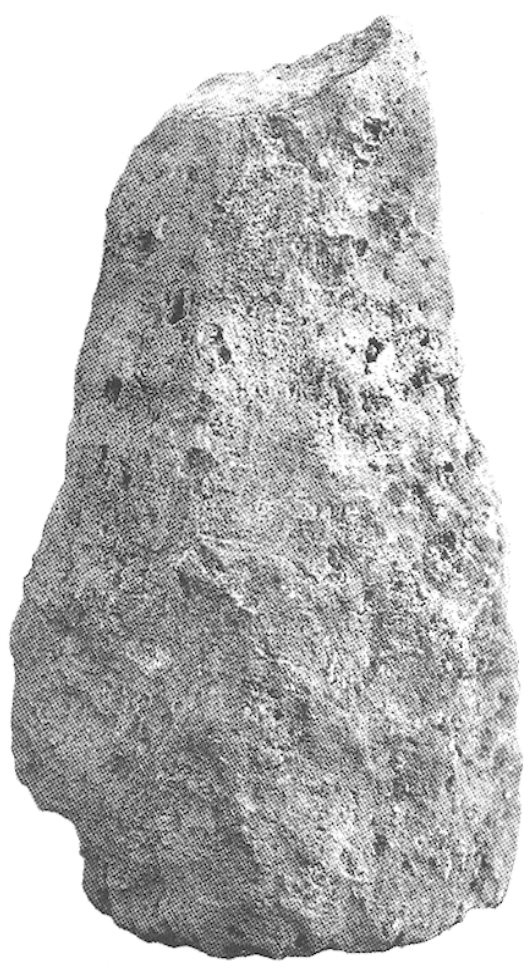

Fig. 70 - Bordeaux (Gironde).

Stèle en calcaire de la Cìté judiciaire (photo P. Texier, INRAP). 


\section{NOTICE 3}

\section{BOURGES (CHER)}

Les fouilles de Bourges mettent au jour depuis une vingtaine d'années les vestiges de deux agglomérations protohistoriques successivement aménagées sur et autour d'un promontoire de confluence, assise de la vieille ville actuelle (Chevrot, Troadec, 1992). La plus ancienne (530420 avant J.-C.) est un pôle proto-urbain de plusieurs dizaines d'hectares formé de différents établissements groupés où l'artisanat et les échanges à longue distance jouent un rôle déterminant (Milcent, 1998). L'agglomération plus récente (II $\mathrm{I}^{\mathrm{er}} \mathrm{s}$. avant J.-C.) est l'oppidum d'Avaricum, la capitale des Bituriges décrite par César (B. G., VII).

Les établissements les plus anciens présentent régulièrement des dépôts entiers ou partiels de corps humains hors contexte funéraire. Les établissements dispersés qui succèdent à la disparition de l'agglomération du Ves. illustrent encore ces pratiques jusqu'au $\mathrm{III}^{\mathrm{e}} \mathrm{s}$. Celles-ci sont d'autant plus spécifiques que des sépultures contemporaines, sous tumulus $\left(\mathrm{V}^{\mathrm{e}} \mathrm{s}\right.$.) puis en tombes plates (IV $\mathrm{I}^{\mathrm{e}}$ III $^{\mathrm{e}}$ s.), sont bien attestées sur le territoire berruyer. La diversité de ces modes de déposition témoigne d'un rapport à la mort et au corps humain complexe et singulier. Sous cet angle, il faut évoquer la découverte récente de traces de travail sur os humains dans l'un des complexes artisanaux du $\mathrm{V}^{\mathrm{e}}$ s. avant J.-C. (information C. TesnierHermetey).

Dans un contexte tout autre, des dépôts d'objets du premier âge du Fer montrent que la zone marécageuse qui enserre le promontoire de Bourges fut aussi le théâtre de dévotions. Quant à l'oppidum d'Avaricum, mal connu par l'archéologie, il livre un probable dépôt de sanctuaire.

\section{CASERne de pompiers des Danjons}

À $3 \mathrm{~km}$ à l'ouest de la vieille ville, ce petit établissement rural de la fin du premier âge du Fer a livré une fosse d'atelier semi-enterré et des silos, dont l'un contenait une inhumation (renseignements A. Luberne).

\section{Les Chassepins}

Cet établissement rural se trouve à $4 \mathrm{~km}$ au sud-est de la vieille ville, et à $400 \mathrm{~m}$ de la batterie de silos du Chemin de Gionne. Il est identifié par des trous de poteaux, sablières basses et fosses d'extraction agglutinées à un vaste enclos fossoyé sans doute palissadé, au tracé très partiellement reconnu dont le comblement recèle de la céramique de
La Tène B2-C1, mais aussi des restes humains : membres d'un même individu; squelette complet d'un sujet masculin âgé, allongé le long de la palissade (Barbé, I uberne, 1988 ; Buchsenschutz, Ralston dir., 2001, p. 29-36).

\section{Chemin de Gionne}

Le site est à $3,5 \mathrm{~km}$ au sud de la vieille ville, en bas de pente, entre l'établissement des Chassepins, à $400 \mathrm{~m}$, et celui des silos de la villa de Lazenay, à $900 \mathrm{~m}$. Une batterie d'au moins 26 silos associée à des fosses d'extraction de sédiment et à quelques trous de poteaux y a été partiellement mise au jour. Les silos furent utilisés pour le stockage végétal, puis comme réceptacles à des dépôts organisés pour au moins neuf d'entre eux. Le matériel cale leur utilisation et leur abandon progressif entre La Tène A ancienne et La Tène C1a (480-250 avant J.-C.) (Delattre, 2000; Buchsenschutz, Ralston dir., 2001). Un puits gallo-romain, avec dans son comblement supérieur un dépôt organisé de crânes d'animaux, est localisé à quelques dizaines de mètres.

On distingue deux types de dépôts humains : quatre silos et une fosse livrent des corps complets ou presque, seuls ou par deux (dont un périnatal), tandis que quatre autres silos et un trou de poteau recueillent des os humains erratiques. Dans le premier cas, des cadavres ont subi diverses manipulations : trois ont eu la tête séparée et déposée à proximité ; un crâne fut prélevé après décollation et décomposition. Rare dans ce type de contexte, du mobilier (La Tène $\mathrm{B} 1$ ancienne) accompagnait trois sujets : un homme portait un bracelet en bronze, une femme deux bracelets, une fibule et une aiguille, un homme un anneau en fer au doigt. Parmi les structures à os humains démembrés, l'une les associerait à un assemblage important de faune (dont de nombreux restes de chevaux, avec des connexions partielles). Des dépôts de bucranes sont identifiés dans d'autres structures. À une exception près, corps humains et crânes de chevaux ont été installés alors que le colmatage des structures avait déjà débuté. Il convient sans doute d'associer à ces abandons organisés de corps et/ou d'ossements des offrandes d'objets. Par exemple, un silo a livré une fibule à timbale et une bouteille en céramique intacte de La Tène $\mathrm{A}$ ancienne (480-420 avant J.-C.).

Dans un second temps, le site, aux silos comblés, fit encore l'objet d'une fréquentation à caractère rituel : un grand fossé d'usage inconnu contenait dans son colmatage initial deux fibules et des restes d'armement, en surface un potin et une fibule de La Tène C2.

Les dépôts les plus anciens peuvent constituer des offrandes propitiatoires : les silos sont des structures à la 
symbolique forte, mettant en jeu la survie de la communauté. On fera ici le parallèle avec quelques-uns des vieux rites agraires romains (Dumézil, 1974, p. 168-169). Dans le calendrier religieux de Rome, deux journées, les Consualia (21 août et 15 décembre), étaient consacrées à Consus, le dieu des moissons mises en réserve. Ce stockage se faisait dans des silos à l'époque archaïque. À cette occasion, le Flamen Quirinalis et les vestales sacrifiaient à un autel souterrain dans le Cirque, là où les cultes étaient rendus aux divinités agraires. Ces fêtes précédaient de peu celles d'Ops (25 août et 19 décembre), déesse personnifiant l'abondance, notamment agricole.

\section{LES ÉTABLISSEMENTS MILITAIRES}

Zone de $700 \mathrm{~m}$ de longueur située au-delà de SaintMartin des Champs, à $600 \mathrm{~m}$ au sud-est du promontoire de la vieille ville, le quartier a été bouleversé pour faire place à des arsenaux au $\mathrm{XIX}^{\mathrm{e}} \mathrm{s}$. On découvrit alors un nombre important d'inhumations du $\mathrm{V}^{\mathrm{e}} \mathrm{s}$. avant J.-C. ensevelies dans des fosses dont la description fait penser à des structures d'atelier ou d'habitat, d'ensilage, voire d'extraction de matériaux. Buhot de Kersers (1879, p. 22) mentionne qu'à cet endroit «se rencontrent des sépultures gauloises, où les squelettes apparaissent jetés sans ordre, plutôt que déposés, dans des trous irréguliers, dont la profondeur varie de $0 \mathrm{~m} 60 \mathrm{c}$ à $1 \mathrm{~m} 50 \mathrm{c}$. Ces squelettes portent des bracelets et des armilles de forme variée [...] ". À la même époque, J. Dumoutet signale la découverte de cinq fossés parallèles entre les Établissements militaires et le site de Saint-Martin des Champs, dans lesquels étaient déposées des inhumations avec du matériel protohistorique. Ces fossés peuvent marquer une limite ou un axe structurant de l'agglomération proto-urbaine du $\mathrm{V}^{\mathrm{e}} \mathrm{s}$. Sur un dessin du même archéologue, on voit trois squelettes parés de bracelets et d'anneaux de cheville et disposés de façon rayonnante dans une fosse polylobée, le crâne vers le centre de la structure. Le matériel associé à ces inhumations est de qualité et abondant: principalement des torques, bracelets et anneaux de cheville du Hallstatt D3 et de La Tène A (Milcent, 1998).

\section{Le Marais de Bourges}

L'éperon sur lequel étaient implantés les centres des deux agglomérations protohistoriques de Bourges domine légèrement un vaste marais de confluence alimenté par l'Yèvre, l'Auron, le Moulon et le Langis. Au XIX ${ }^{e}$ s., des aménagements dans cette dépression palustre provoquèrent la trouvaille de plusieurs objets remarquables: une épée intacte à pointe en langue de carpe (Hallstatt B2-3) associée à trois pieux de bois alignés ; un rasoir centre-italique plié (Hallstatt C) ; un poignard brisé à antennes de la région du Hohenasperg dans le Wurtemberg (Hallstatt D2) (Milcent, 1998).

Les objets mis au jour, tous importés, faisaient partie d'équipements aristocratiques et correspondent probablement à des offrandes en milieu humide (voir partie sur les dépôts en milieu humide dans la synthèse). Les pieux en bois purent faire partie d'un aménagement cultuel, un ponton par exemple, comme on en connaît dans plusieurs sanctuaires liés aux eaux stagnantes.

\section{Rue de La Nation}

À l'extrémité et sur la pente occidentale du promontoire de l'oppidum, un dépôt d'époque laténienne installé dans une légère dépression a été mis au jour, et interprété comme celui d'un sanctuaire exposé pour partie à l'air libre, mais peut-être associé à un édicule dont subsisterait un trou de poteau (Ruffier, 1990).

Les vestiges comprennent de la faune, notamment des crânes de plusieurs dizaines de porcs adultes " en connexion anatomique ", des mandibules d'ovi-caprinés et métapodes de boufs ou chevaux, mais aussi de la parure (perle de verre), de l'outillage, des objets divers en fer et de l'armement mutilé. Une bouterolle d'épée caractéristique de La Tène $\mathrm{D}$ date le dépôt des années 12030 avant J.-C.

\section{SAINT-Martin des ChampS}

Un complexe artisanal de La Tène A ancienne, à $500 \mathrm{~m}$ au sud-est de la vieille ville, a donné une inhumation de périnatal dans le colmatage (calage ?) d'un trou de poteau (Service municipal d'archéologie, en préparation).

\section{VILLA DE LAZENAY}

Trois silos mis au jour à proximité d'une villa galloromaine correspondent à une batterie d'ampleur inconnue. Le site est à $3,5 \mathrm{~km}$ au sud de la vieille ville et à $900 \mathrm{~m}$ au nord-ouest des structures d'ensilage du Chemin de Gionne. Deux de ces silos renfermaient une inhumation et quelques tessons qui datent les dépôts de La Tène B ou La Tène C1 (Buchsenschutz et al., 1999 ; Buchsenschutz, Ralston dir., 2001, p. 77-79).

Bibliographie : Barbé, Luberne, 1988 ; Ruffier, 1990 ; Chevrot, Troadec, 1992 ; Milcent, 1998; Buchsenschutz et al., 1999 ; Delattre, 2000 ; Buchsenschutz, Ralston dir., 2001.

P.-Y. MIL.CENT 


\section{NOTICE 4}

\section{CHÂTEAUMEILLANT (CHER)}

\section{LE JARDIN KASMAREK}

Châteaumeillant (Mediolanum, littéralement le " centre sacré ") est l'un de ces quelques oppida du domaine laténien occidental dont l'occupation remonte à la première moitié du $\mathrm{II}^{\mathrm{e}}$ s. avant J.-C., comme l'atteste un nombre considérable d'amphores gréco-italiques. Un murus gallicus qui n'est pas antérieur à La Tène D1b contribue à défendre au ${ }^{\mathrm{Ir}} \mathrm{s}$. avant J.-C. une surface de l'ordre de 18 ha. Depuis le $\mathrm{XIX}^{\mathrm{e}}$ s., quelques centaines d'amphores ont été retrouvées, souvent intactes aver leur bouchon ou décolletées dans des fosses quadrangulaires ou cylindriques. Le remplissage de ces structures pose des difficultés d'interprétation: certaines accumulations pourraient correspondre à des abandons intentionnels et symboliques, mais, dans l'état de l'information, un seul dépôt en puits paraît assurément rituel. La structure fut mise au jour dans la partie sud de l'oppidum, dans le Jardin Kasmarek. Il s'agit vraisemblablement d'un puits à eau de $4 \mathrm{~m}$ de profondeur dans lequel le remplissage supérieur fait apparaître un dépôt en plusieurs couches, en haut de " nombreux andouillers de cerf » dans une couche cendreuse, en bas un bouchon de grosses pierres parmi lesquelles une statue (Hugoniot, Gourvest, 1961).

Le bloc sculpté, en grès fin, de $25 \mathrm{~cm}$ de haut, représente le buste d'un personnage aux bras croisés sur la poitrine avec un torque au cou. Des chevrons ébauchés sur les côtés peuvent correspondre à la décoration des montants d'un siège ou, plutôt, aux plis des manches d'un vêtement. La base en est brisée.

L'association de la statue avec des ramures de cervidé n'est aucunement fortuite et se retrouve à Levroux (Indre) ainsi que dans le puits 4 du Crêt-Châtelard à Saint-Marcelde-Félines (Loire). En outre, d'autres exemples de dépôts symboliques au sommet de comblements de puits sont attestés, notamment à Agen. La statue de Châteaumeillant appartient sans doute à la série des "bustes sur socle enterrés " définie par Y. Ménez (1999) et interprétée comme des effigies d'ancêtres.

Les céramiques trouvées sous le dépôt supérieur du puits, des sigillées arétines notamment, datent de la période 30-10 avant J.-C. Toutefois, le buste a sans doute été sculpté bien avant qu'il ne soit précipité dans le puits, probablement à l'époque laténienne.

Bibliographie : Hugoniot, Gourvest, 1961.

P.-Y. MILCENT
NOTICE 5

\section{COURCOURY (CHARENTE-MARITIME)}

\section{LE Terrier de la FAde}

Le Terrier de la Fade est un énorme tumulus repéré de longue date. Des fouilles partielles conduites de 1965 à 1975 n'ont décelé aucune sépulture. Le site qui l'environne et auquel il donne son nom est célèbre pour les trouvailles de deux dépôts de monnaies celtiques du type Regenbogenschüsselchen et petits lingots d'or (Hiernard, 1999).

La découverte fortuite d'une sépulture à incinération déposée dans une fosse et probablement contenue dans un bassin en bronze de type étrusque, et accompagnée de céramiques dont une coupe massaliète, avait suscité en 1994 une fouille de contrôle limitée (Gomez de Soto, Vernou, 1999). La mise en évidence par prospection aérienne d'une nécropole-sanctuaire à enclos fossoyés, dont l'un (enclos I) entourait l'emplacement de la tombe, justifia de nouvelles recherches, dans le dessein de compléter la connaissance de l'ensemble funéraire déjà identifié. À cette occasion, un Langgräbe datant vraisemblablement du Bronze final fut reconnu.

Le fossé périphérique de l'enclos I possède des caractères bien connus pour un certain nombre de sites régionaux comme plus généralement d'Europe occidentale, tels que présence vraisemblable d'une palissade, dépôts de fondation (avec ici des restes fauniques à forte connotation symbolique : fragments d'un crâne de cheval), etc.

Au IV' s. avant J.-C., le fossé non encore complètement comblé reçut de petits dépôts, dont un fragment d'une lame d'épée ayant subi des mutilations et une portion d'écuelle aux fragments éparpillés. Cette intervention s'est effectuée dans le secteur sud-est de l'enclos, un emplacement à forte connotation symbolique solaire coincidant d'ailleurs assez exactement avec celui des dépôts de fondation du $\mathrm{VI}^{\mathrm{e}} \mathrm{s}$. Un gros bloc d'aspect anthropomorphe trouvé au sommet du remplissage du fossé, très près du nord magnétique actuel, pourrait être une stèle, rappelant les probables stèles brutes de Roullet-Saint-Estèphe (Boguszewski et al., 2001), et est à rapprocher des cippes de Bordeaux et de Roullet-SaintEstèphe.

Le fragment d'épée de La Tène B2 évoque ces petits dépôts d'armes mutilées découverts en dehors des grands sanctuaires, qui constituent autant de témoignages de pratiques cultuelles. Les autres exemples du Centre-Ouest, des Pays de Loire et du Centre (Font Barbot à Pons ; Le Chemin Chevaleret à Échiré ; Les Genâts à Fontenay-leComte; Beuzons à Écouflant et Levroux) sont plus récents que celui de Courcoury. 
Surtout, ces dépôts apportent un arrière-fond cultuel à la découverte des dépôts d'or du $\mathrm{II}^{\mathrm{e}} \mathrm{s}$. avant J.-C. dans l'emprise de la nécropole ou du moins sa proximité immédiate, qui se trouvent ainsi inscrits dans un contexte à forte connotation religieuse initiée par la mise en place d'une nécropole-sanctuaire probablement dès le Bronze final, sept siècles plus tôt au moins. Une telle pérennité cultuelle pluriséculaire rappelle celle d'autres nécropolessanctuaires du Centre-Ouest, telles Antran, CivauxValdivienne ou Ribérolles à Rivières.

Bibliographie : Hiernard, 1999; Gomez de Soto, Vernou, 1999 ; Boguszewski et al., 2001.

J. GOMEZ DE SOTO

\section{NOTICE 6}

\section{ÉCHIRÉ (DEUX-SÈVRES)}

\section{Le Chemin Chevaleret}

Le site du Chemin Chevaleret à Échiré est un établissement rural des II $^{e}$ et I ${ }^{\text {er }}$ s. avant J.-C. (Cornec, 2000 ; Poux et al., 2000).

Le mobilier de ce site est étonnant : 3214 tessons de céramique indigène pour 3135 tessons d'amphores. Ces dernières ont fait l'objet de tri et certains dépôts sont organisés en fonction de la morphologie des fragments. Comme pour le site des Genâts à Fontenay-le-Comte, certains tessons sont de très petites dimensions et brûlés. L'énorme quantité d'amphores et leur manipulation (destruction avec des outils, dépôts organisés) permettent d'évoquer plus qu'une simple consommation domestique une pratique rituelle liée au banquet. L'exemple le plus frappant dans la transformation des containers usagés est illustré par une représentation anthropomorphique ithyphallique gravée sur une anse. Le reste du mobilier est également particulier: $56 \%$ des objets métalliques proviennent de trous de poteaux. Pour certains, il s'agit de pièces jamais mentionnées dans les établissements ruraux, tels cureoreilles ou style. Les autres pièces sont plus ordinaires (bracelet à jonc plein cannelé, forces, couteaux, gouttière de bouterolle, monnaie) mais elles proviennent de trous de poteaux. Il est vraisemblable qu'il s'agisse de dépôts volontaires.

Dans le cas du Chemin Chevaleret, on a affaire à un habitat de type " aristocratique " et non à un sanctuaire. Cependant, dans ce cadre domestique, on décèle des pratiques particulières relevant de rites sociaux ou religieux. Bibliographie : Cornec, 2000 ; Poux et al., 2000.

O. Nillesse

\section{NOTICE 7}

\section{LEVROUX (INDRE)}

\section{LES ARÈneS}

Cette agglomération ouverte d'une superficie d'environ 8 ha est fondée à la fin de La Tène C1 (vers 200 avant J.-C.), puis abandonnée dans le courant de La Tène Dlb (vers 9080 avant J.-C.) sans doute au profit de l'oppidum de la Colline des Tours. Les zones fouillées présentent des trous de poteaux, des tranchées de fondation et de nombreuses fosses. Les remplissages de ces dernières sont surtout des rejets d'activités artisanales, mais plusieurs assemblages insolites d'objets renvoient sans doute à des pratiques symboliques : dans un cas il s'agit du dépôt d'une statuette, ailleurs, de dépôts de monnaies.

La statuette de la fosse PH 14 est un buste mutilé en calcaire de $23,50 \mathrm{~cm}$ de hauteur, trouvé déposé face contre terre. Parmi les objets d'accompagnement, dont diverses pièces en fer et alliage cuivreux, figurent un polissoir en grès, un bloc en pierre perforé, un moule à alvéoles, un potin biturige, des tessons d'amphores et une ramure de cervidé intacte. Ce mobilier est attribué à la dernière occupation laténienne du village, à La Tène D1b. La sculpture, compte tenu de son état, paraît plus ancienne (seconde moitić du II's. avant J.-C. ?). Le caractère remarquable de l'assemblage (statue et ramure de cervidé), connu aussi dans le puits du Jardin Kasmarek à Châteaumeillant, montre qu'il s'agit d'un dépôt symbolique.

Les quatre dépôts de monnaies, bien que non contemporains, présentent des particularités laissant supposer qu'il ne s'agit pas de simples cachettes. L'un provient d'une grande fosse, les trois autres de trous de poteaux. La fosse prend place à l'intérieur d'espaces quadrilatéraux clos de palissades, un trou de poteau est placé au seuil du dispositif en couloir permettant l'accès à ces lieux fermés, un autre semble appartenir à un bâtiment rectangulaire.

La fosse R 127 contenait trois quarts de statères en or, vingt-cinq monnaies d'argent, de nombreux tessons de céramiques, des objets en fer, de la faune. Le mobilier céramique est attribué à La Tène C2. Le trou de poteau R 333 du seuil d'une entrée en couloir n'a produit qu'une pièce, une monnaie d'argent fleur de coin datée vers le milieu du $\mathrm{II}^{\mathrm{e}} \mathrm{s}$. avant J.-C. Une autre empreinte de poteau (CG 403) recelait un potin, trois monnaies de bronze frappé ainsi que des tessons d'amphores, soit un matériel attribuable à Ia Tène D1. Cinq mètres plus loin, un trou de poteau (CG 427) recueillait une monnaie d'argent, vingtneuf bronzes frappés, cinq potins, des tessons d'amphores et 
divers objets en fer dont des pièces d'armement. Ce dépôt se rattache également à La Tène Dl.

Ces différents ensembles rendent compte d'activités de nature symbolique, au moment de l'aménagement du site ou de sa reconstruction (rites de fondation avec dépôt dans les trous de poteaux ?), ainsi qu'au cours de son utilisation.

Bibliographie : Buchsenschutz et al., 1994, 2000 ; Krausz et al., 1989.

\section{P.-Y. MILCENT}

\section{NOTICE 8}

\section{MÉRIGNY (INDRE)}

\section{Grotte de LA Roche NoIRE}

Cette cavité d'un réseau karstique traversé par un bras souterrain de l'Anglin présente des boyaux comportant trois élargissements principaux, les salles 1,2 et 3 . Certains diverticules ont été utilisés pour y déposer restes humains, faune et mobilier. Les vestiges étaient groupés dans la salle 1 et surtout dans la salle 2 . Dans le lit même du ruisseau gisaient des restes humains et du mobilier dont un conglomérat d'objets métalliques. Il est vraisemblable que la majorité du matériel ait été entraînée dans le lit du cour's d'éau pendant des périodes de crues. Ces dernières sont également responsables de la dispersion des vestiges sur les berges (Cordier, 1978 ; Lorenz et al., 1984).

D'après les pièces crâniennes, on estime le nombre minimum des sujets déposés à douze adultes et sept enfants. Des os de faune représentant vingt-cinq animaux (bovins, porcins, ovicaprinés, canidés), dispersés un peu partout, accompagnaient parfois les vestiges humains.

La vaisselle est représentée par vingt-deux récipients parfois complets en céramique fine ou grossière et par de nombreux tessons isolés ou ne pouvant se rapporter à un vase précis. Les parures et amulettes sont deux anneaux en bronze, une petite sphère en bronze, un demi-bracelet en lignite, une défense de sanglier, un scaphoïde de bœuf perforé et un coquillage méditerranéen. Le reste du mobilier est représenté par quelques outils et armes - une pointe de lance, un couteau en fer associé à un bloc en calcaire poli - et par un amas de métal soudé par l'oxydation, qui constitue un petit dépôt regroupant deux débris de bracelets en fer, deux fibules en fer et deux en bronze. Le matériel, homogène, suppose une utilisation assez brève que les fibules placent à La Tène A ancienne.

Bien qu'elle ait été identifiée comme un simple gisement funéraire, la grotte de La Roche Noire présente des caractéristiques qui ne sont pas celles d'une simple nécropole. $\mathrm{R}$. Riquet qui étudia les os humains admettait que « le désordre des ossements n'est pas en faveur de vraies sépultures mais plutôt d'un dépôt. Ajoutons que les os longs ne sont pas en proportion des crânes ce qui pourrait évoquer l'idée de "sépultures secondaires" " (Lorenz et al., 1984, p. 104). Le contenu de la grotte, à une époque où la norme est d'inhumer les défunts dans une tombe plate ou en tumulus, sans aucune offrande alimentaire, évoque plutôt un système complexe de déposition de nature à la fois religieuse et peut-être funéraire, dont on connaît d'autres exemples à l'âge du Fer dans les grottessanctuaires.

Bibliographie : Cordier, 1978 ; Lorenz et al., 1984.

P.-Y. MILCENT

\section{NOTICE 9}

\section{MURON (CHARENTE-MARITIME)}

\section{Les Prés de LISE}

Muron est une petite agglomération du second âge du Fer et de la période gallo-romaine dont sont connus l'habitat, des sites à sel, des nécropoles, un établissement rural fossoyé et un sanctuaire.

Un sauvetage sur le sanctuaire laténien fut limité à la zone de concentration maximale des trouvailles en surface, cœur présumé du site.

Ses limites exactes ne sont pas connues avec précision : les détections aériennes n'ont pas donné de résultat, la fouille n'a permis de repérer un fossé présumé de clôture (ou une fosse profonde: la modicité de la largeur du sondage ne permet pas de trancher) qu'à l'est. Cette structure a livré, en particulier, une grande pointe de lance mutilée (Gomez de Soto, 1989, 1991 ; Gomez de Soto, Lejars, 1991).

Divers types de structures ont pu être reconnus :

- des sols anciens bien conservés avec par place des radiers de cailloux de calcaire rappelant ceux de Dompierre-surAuthie en Picardie ou de Bourges, ou des nappes de pierres plus volumineuses et moins régulièrement organisées. À l'extérieur de ces empierrements, restes de faune, tessons de céramique, pièces métalliques sont nombreux, alors qu'ils sont nettement plus rares dessus ;

- des fosses masquées par des nappes de pierres. Celle qui a été fouillée contenait une amphore dépourvue de son ouverture et d'autres tessons d'amphores et de céramique locale, des restes de faune dont un crâne de cheval sans mandibule, de nombreuses pièces d'armement et des débris 


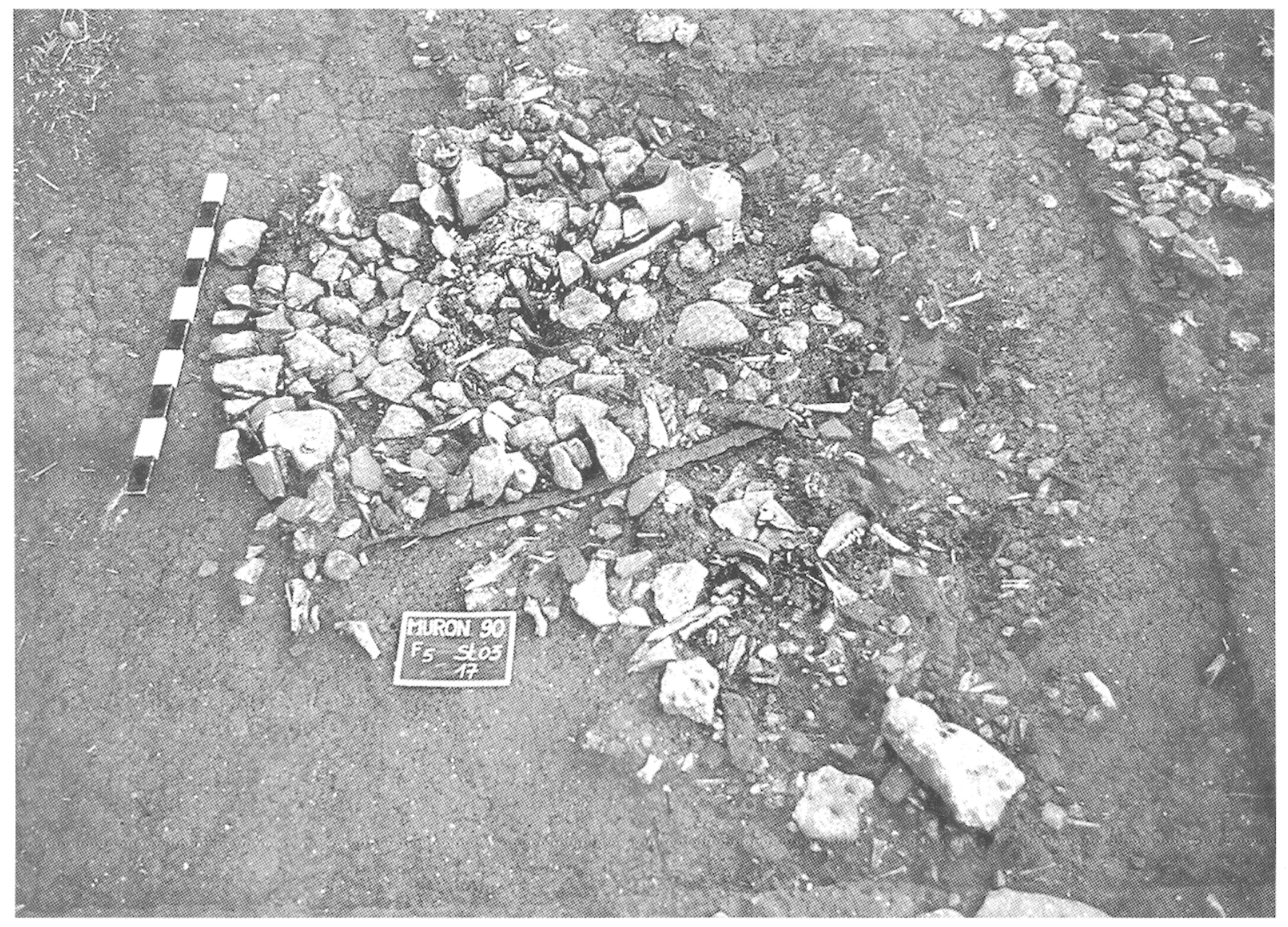

Fig. 71 - Muron (Charente-Maritime). Sommet du remplissage d'une fosse du sanctuaire des Prés de Lise : amphores, faune (dont un crâne de cheval), armes et outils en fer, fragments d'un chaudron en bronze, tessons (photo J. Gomez de Soto, CNRS).

d'un chaudron en bronze (fig. 71). Il s'agit probablement d'une favissa (Poux, 2000a et b).

Le mobilier laténien est riche et varié : amphores, céramique locale, faune, pièces d'armement souvent mutilées volontairement, outils, verre, monnaies. Le nombre important des outils fait l'originalité de ce sanctuaire (Thonont, 2001).

Les plus anciens éléments remontent au IVe $\mathrm{s}$., comme à Saint-Jean-Trolimon (Finistère), célèbre pour des fragments de casques et plusieurs ouvres d'art du Style Végétal Continu. La majorité des matériaux date toutefois de La Tène $\mathrm{C}$ et de La Tène $\mathrm{D}$.

Pendant la période gallo-romaine, la fréquentation du sanctuaire s'est poursuivie. Le site se dota alors de constructions en pierre.

Bibliographie : Gomez de Soto, 1989, 1991 ; Gomez de Soto, Lejars, 1991 ; Poux, 2000a et b ; Thonont, 2001.

J. GOMEZ de SOTO
NOTICE 10

\section{SAINT-GEORGES-DE-DIDONNE (CHARENTE-MARITIME)}

\section{LE SANCTUAIRE}

Le site, découvert par J. Dassié lors d'une prospection aérienne, a fait l'objet d'une intervention archéologique préventive en 1999, qui a mis au jour plusieurs phases d'occupation protohistorique, médiévale et moderne (Baigl et al., 1999). Seuls seront présentés ici les vestiges protohistoriques, trois enclos quadrangulaires situés à l'intérieur d'une vaste enceinte (fig. 72).

La portion connue du fossé d'enceinte, orientée estouest, est parfaitement rectiligne sur les $200 \mathrm{~m}$ de longueur observés. Sa largeur est constante, $80 \mathrm{~cm}$, sa profondeur conservée varie entre 30 et $40 \mathrm{~cm}$. Il possède une interrup- 


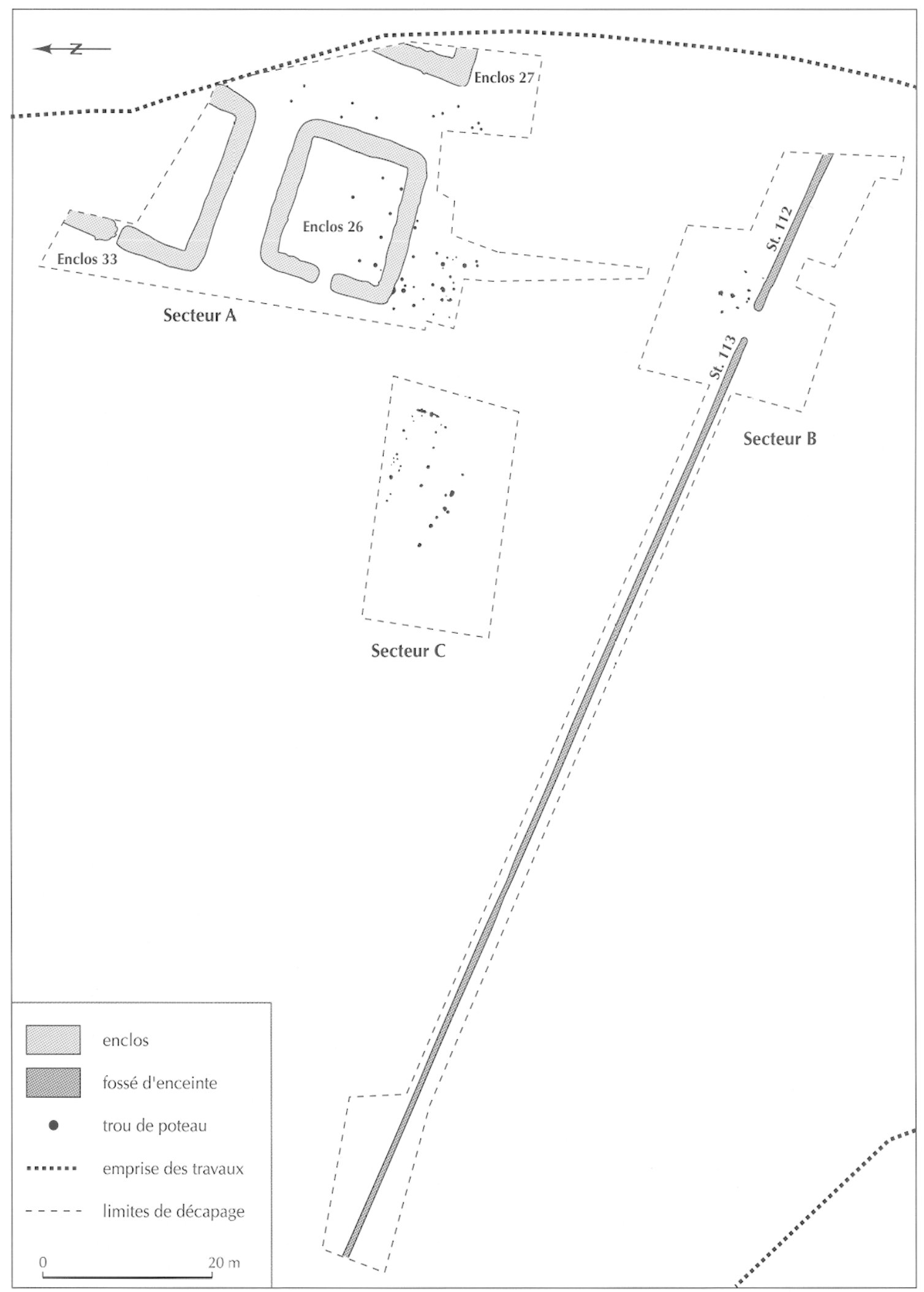

Fig. 72 - Saint-Georges-de-Didonne (Charente-Maritime). Plan d'ensemble du sanctuaire (dessin S. Boulogne, INRAP). 
tion de $3 \mathrm{~m}$ environ de largeur pouvant correspondre à l'accès aux enclos. L'observation du remplissage a permis de reconnaître l'existence d'une palissade.

Un seul des trois enclos quadrangulaires mis au jour a été dégagé complètement (st. 26). Il mesure $16 \mathrm{~m}$ sur $17,50 \mathrm{~m}$ et possède sur sa face occidentale une entrée de $1 \mathrm{~m}$ de largeur environ. Les deux autres (st. 27 et 33) s'étendent en partie hors de l'emprise des travaux. Le plus complet, l'enclos 33, possède également une entrée, large seulement de $50 \mathrm{~cm}$, sur le même côté que l'enclos 26 . En revanche, son côté méridional, dégagé entièrement, qui atteint $20 \mathrm{~m}$, est plus grand que celui de l'enclos 26. L'enclos 27 n'est connu que par son angle sud-ouest, il est impossible de savoir s'il possède également une entrée. La largeur des fossés, environ $2 \mathrm{~m}$, est semblable pour chacun des enclos, mais les profondeurs conservées diffèrent : autour de $50 \mathrm{~cm}$ pour l'enclos 26,50 à $80 \mathrm{~cm}$ pour l'enclos 33 et 60 à $80 \mathrm{~cm}$ pour l'enclos 27.

Seul l'intérieur de l'enclos 26 a été décapé entièrement. Aucune fosse, funéraire ou autre, n'y a été mise au jour. Les seules structures présentes s'identifient à des trous de poteaux, mais leur disposition ne permet pas de proposer un plan de bâtiment. De plus, il n'est pas absolument certain que ces structures soient strictement contemporaines des enclos: d'autres trous de poteaux sont présents également à l'extérieur à proximité dans le secteur A ou un peu plus loin dans le secteur C (fig. 72). Ils sont plus nombreux et disposés de façon plus dense qu'à l'intérieur des enclos mais, là non plus, il n'est pas possible de lire d'agencement particulier. De plus, le décapage n'étant pas exhaustif, certaines structures se situent à proximité des limites de décapage.

Il apparaît une grande homogénéité dans le remplissage des fossés, à l'intérieur d'un même enclos et également d'un enclos à l'autre. En effet, on retrouve dans toutes les coupes : un niveau de base peu épais issu de l'érosion des parois (séquence 2) ; une ou plusieurs couches très caillouteuses dont la matrice est composée d'un sédiment compact gris (séquence 3 : utilisation) ; des couches plus terreuses, généralement argilo-sableuses de couleur brune en partie sommitale du comblement (séquences 4 et 5 : remblais).

La céramique représente le mobilier le plus abondant (1 500 tessons pour les trois enclos). La répartition par séquence reste globalement équivalente pour chaque enclos : la séquence 2 est très pauvre ( 0,5 à $2 \%$ des tessons), la séquence 3 en possède entre 15 et $30 \%$ et les séquences 4 et 5 , de 65 à $80 \%$. La proportion importante de la céramique des séquences 4 et 5 peut certainement s'expliquer par le volume important de ces ensembles au sein du comblement des fossés. Aucun vase entier n'est à signaler, au contraire les tessons marquent une fragmentation importante. Ils sont de plus éparpillés de façon homogène: l'analyse spatio-quantitative n'a en effet pas montré de zones plus denses, comme dans les entrées ou les angles, par exemple, hormis dans l'angle de l'enclos 27 qui a livré deux parties supérieures de vases brisés sur place qui peuvent être assimilées à un dépôt.

La série peut être datée de la fin du premier âge du Fer ( $\mathrm{VI}^{\mathrm{e}}$ ou début du $\mathrm{V}^{\mathrm{e}}$ s. avant J.-C.), avec des éléments résiduels de l'âge du Bronze ancien ou moyen, occupation par ailleurs mise en évidence dans un autre secteur du gisement.

Les os de faune proviennent en très grande majorité de la séquence 3 du remplissage des fossés (fig. 73). Il s'agit le plus souvent d'os entiers, trouvés en général à la surface des couches de cailloux composant cette séquence. Ainsi les caractéristiques et la position de ces couches au sein du comblement permettent de proposer que ces os appartiennent à des dépôts. De plus, on reconnaît une très forte proportion de mandibules : 15 mandibules sur les 21 os appartenant à des dépôts. Il s'agit semble-t-il en majorité de mandibules et d'hémi-mandibules de bovidés : des hémimandibules isolées (12 cas), parfois une mandibule complète en connexion ( 2 cas), un cas d'association de trois hémi-mandibules. On note également pour la séquence 3 dans l'enclos 27 la présence d'un squelette de canidé en connexion, à rapprocher du chien inhumé à Roullet-SaintEstèphe (Boguszewski et al., 2001).

Il n'cxistc pas d'cmplacement privilégié de dépôt dans l'enclos 26, fouillé entièrement. Aucun dépôt n'a été attesté pour les séquences 4 et 5 , en revanche un dépôt constitué de deux omoplates ou coxaux a été découvert près de l'entrée de l'enclos 33.

Le mobilier métallique se résume à une pointe de flèche à pédoncule et ailerons en bronze dans l'enclos 27, dans la séquence 5 , dernière phase de comblement du fossé. Aucun fragment d'os humain n'a été trouvé.

Les trois enclos de Saint-Georges-de-Didonne semblent identiques tant par leur morphologie, le type de leur remplissage, leur fonction, que leur date. Malgré leur fouille incomplète et donc les incertitudes concernant la présence et l'organisation d'éventuels autres vestiges, les données observées mettent en évidence un sanctuaire de la fin du premier âge du Fer. La date relativement haute de ces structures quadrangulaires est intéressante, puisque peu d'enclos de ce type ont été reconnus pour cette période dans la région PoitouCharentes. En Saintonge, un de Port-d'Envaux faisait partie d'un ensemble cultuel lié à une nécropole (Coulaud et al., 1983), un autre associé à un enclos circulaire a été découvert à La Tremblade (Baigl, 2000b). D'autres ont été identifiés en Angoumois comme en Poitou (Gomez de Soto, Pautreau, 2000). À cette ancienneté des enclos fossoyés quadrangulaires en Centre-Ouest répondent encore, dans le monde 


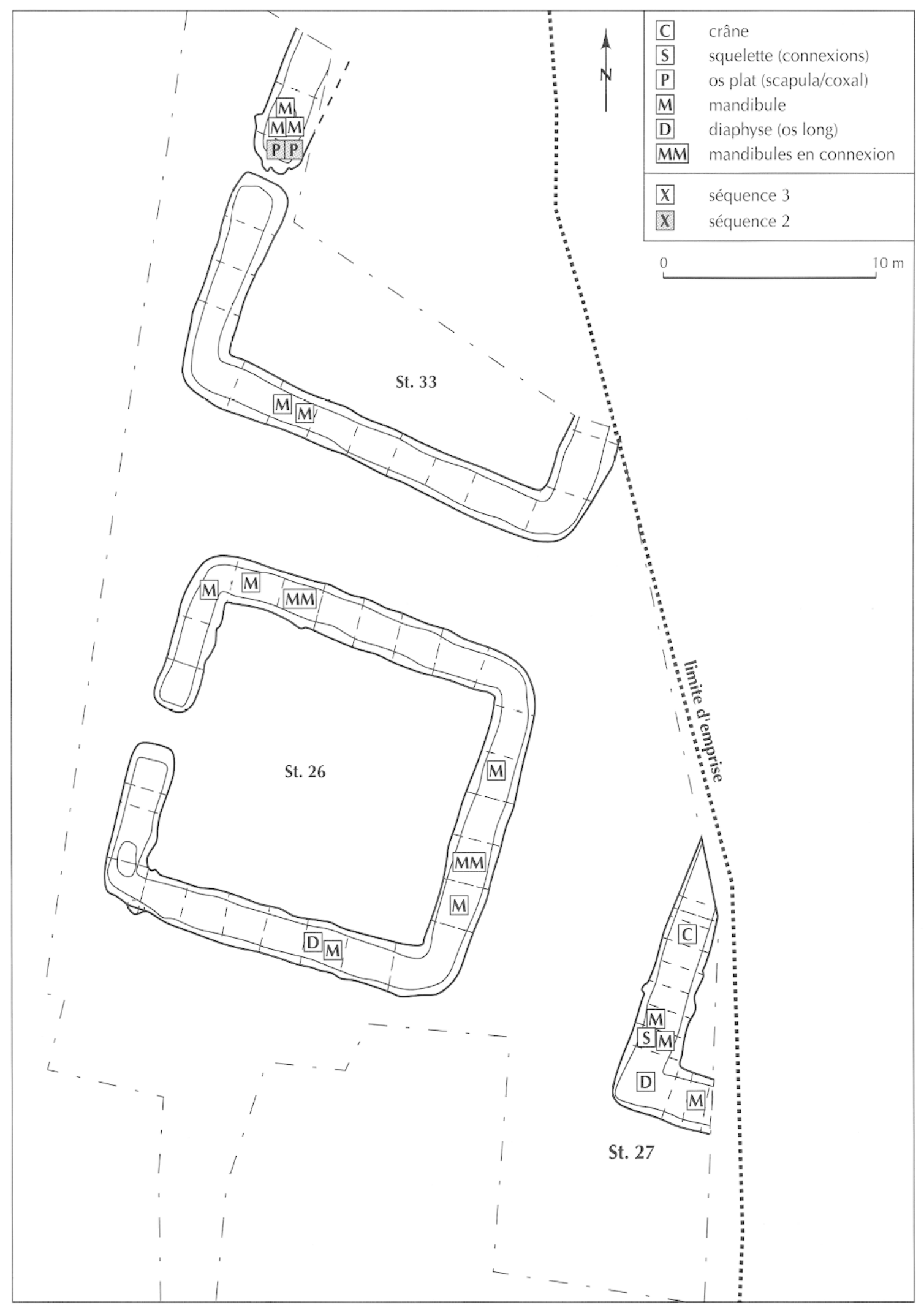

Fig. 73 - Saint-Georges-de-Didonne (Charente-Maritime).

Répartition des dépôts de faune dans les fossés des enclos (dessin S. Boulogne, INRAP). 
atlantique, des enclos comme ceux de Kerviguérou à Melgven dans le Finistère (Daire, Villard, 1996, p. 127).

Bibliographie : Coulaud et al., 1983 ; Daire, Villard, 1996 ; Baigl el al., 1999 ; Baigl, 2000b ; Gomez de Soto, Pautreau, 2000 ; Boguszewski et al., 2001.

J.-P. BAIGL

\section{NOTICE 11}

\section{SAINT-MARCEL (INDRE)}

\section{L'OPPIDUM DES MERSANS}

Le plateau des Mersans à Saint-Marcel fait assiette à un oppidum gaulois de 27 ha défendu par un murus gallicus dont la fondation ne semble guère antérieure à la fin de La Tène D1. Si l'agglomération gallo-romaine d'Argentomagus a détruit ou masqué l'essentiel de l'implan-tation laténienne, la découverte de nombreux objets gaulois à l'emplacement des fana et de la fontaine monumentale laisse présumer l'existence de lieux de culte protohistoriques.

Sous les vestiges des temples du $\mathrm{I}^{\mathrm{er}}$ s. subsistent les vestiges d'un sol plus ancien, avec des trous de poteaux dont certains comportaient dans leur calage des tessons d'amphores. Un mobilier abondant de La Tène $\mathrm{D} 2$, voire de La Tène $\mathrm{D} 1 \mathrm{~b}$, figure dans ce sol ou en contexte résiduel: fibules de Nauheim, fibules filiformes en fer, fibules Almgren 65, tronçon de bracelet et perles en verre, fragment de bracelet en bronze, perle d'ambre, crochet de ceinturon d'épée, pouciers de passoire à vin et nombreux fragments d'amphores républicaines. Ce matériel présente un faciès comparable à celui exhumé sur le sanctuaire de Corent (La Tène D2) dans le Puy-de-Dôme (informations M. Poux).

Au niveau de la fontaine, d'autres éléments suggèrent le déroulement de pratiques festives : sur un sol jonché de débris d'amphores de type Dressel 1B figurent un poucier de passoire à vin en bronze, un support de seau ou situle en bronze et divers objets.

Bibliographie : Fauduet, 1992.

\section{P.Y. MILCENT}

\section{NOTICE 12}

\section{SOINGS-EN-SOLOGNE (LOIR-ET-CHER)}

\section{La Ferme du Chastelluer}

L'agglomération secondaire gallo-romaine de Soings, reconnue depuis le $\mathrm{XIX}^{\mathrm{c}}$ s., présente des indices d'une occupation antérieure d'époque laténienne. Au lieu-dit La Ferme du Chastellier, en 1826, furent dégagées des fondations antiques, notamment celles d'un fanum. En outre, fut mis au jour parmi les substructions un dépôt d'objets en or (La Saussaye, 1836, pl. II ; Florance, 1926, p. 259-260). De cette trouvaille, on ne conserve que quelques pièces et un inventaire :

- « un grand nombre » de monnaies dont ne subsistait un an après la découverte qu'un "petit nombre ", soit huit statères imités du type de Philippe II de Macédoine ;

- un torque massif, avec un jonc « de la grosseur d'un petit doigt » terminé par "deux boules creuses » ressemblant aux "pavillons d'un cornet [...] tordu en plusieurs endroits ".

Les monnaies datent vraisemblablement d'une époque antérieure à La Tène $\mathrm{D}$. La description du torque est aussi en faveur d'une datation ancienne, III' ou première moitié du II ${ }^{c}$ s. avant J.-C. Un dépôt comparable - un torque, un bracelet en or et 85 statères du type de Philippe II - provient de Saint-Gérand-de-Vaux dans l'Allier, dans une zone qui participe aussi des frontières de la cité des Bituriges (Pion, 1984 , p. 54, pl. 53).

Outre le contexte (réoccupation du site par un sanctuaire gallo-romain), l'hypothèse que les objets d'or forment une offrande religieuse est confortée par la découverte dans l'ensemble du monde laténien d'autres dépôts formés selon des règles consistant à associer des monnaies, parfois de petits lingots en or ou argent, à une ou plusieurs parures en or rendues inutilisables (Fürger-Gunti, 1982). Plusieurs de ces trésors ont d'ailleurs été mis au jour en contexte de sanctuaire laténien à Ribemont-sur-Ancre (Somme) et Snettisham (Norfolk). Cet usage d'associer dans l'offrande un stock de métal, sous forme de lingots et/ou des objets à valeur d'échange (monnaies, haches, etc.), à un ou plusieurs objets issus d'un équipement personnel, telles une parure précieuse, une arme, s'inscrit dans des traditions attestées au moins dès l'âge du Bronze ancien (Verger, 1992).

Bibliographie : La Saussaye, 1836 ; Florance, 1926 ; FürgerGunti, 1982 ; Pion, 1984 ; Verger, 1992.

P.-Y. MILCENT

\section{NOTICE 13}

\section{TOULOUSE ET VIEILLE-TOULOUSE (HAUTE-GARONNE)}

Les recherches sur les puits gaulois du Toulousain ont beaucoup pâti d'une tendance à la systématisation des interprétations. Les qualificatifs qui leur ont été appliqués (puits funéraires, puits rituels, puits à offrandes, puits à 
amphores...) ont toujours été univoques et exclusifs, au point que l'on a fini par oublier qu'il s'agissait d'un ensemble de structures extraordinairement variées. Tout bien considéré, leur seul véritable point commun réside dans le mode de construction : section carrée de $0,80 \mathrm{~m}$ à $1,10 \mathrm{~m}$ de côté dans la grande majorité des cas, parois verticales jamais maçonnées, parfois cuvelées en bois. Pour le reste, c'est-à-dire pour tout ce qui concerne la stratigraphie et le contenu du remplissage, la diversité est confondante. Il suffit pour s'en convaincre de se reporter aux nombreuses sections stratigraphiques publiées par M. Vidal (1977, 1989), pour les puits du quartier Saint-Roch au sud de l'agglomération toulousaine (abrégé ci-après SR) comme pour les puits du coteau de Vieille-Toulouse, $6 \mathrm{~km}$ plus au sud (abrégé VT). Le fond de certains puits présente un dépôt organisé recouvert par des couches de comblement très pauvres en mobilier (SR 26, VT 24); d'autres, à l'inverse, aucun dépôt initial et un remplissage riche en mobilier (SR 13, VT 15, 30, 31, 44) ; d'autres enfin - ceux que l'on cite le plus souvent, mais qui ne forment qu'une catégorie parmi d'autres - ont à la fois un dépôt organisé au fond et un remplissage varié (par exemple : SR 2, 5, 10, 25 ; VT 14, 16, 25, 39). Quant au dépôt de la couche initiale, on trouve toutes les combinaisons imaginables entre un pot unique en céramique indigène (VT 37) et un ensemble très riche comportant, outre de la vaisselle en céramique et en bronze, des éléments d'armement (VT 16, 23, et Estarac 9).

En dépit de cette diversité, qui défie toute tentative de restitution d'un scénario type applicable à l'ensemble des puits, on a toujours considéré que les puits du Toulousain témoignaient d'un acte rituel unique et limité dans le temps. Pour les uns cet acte est funéraire, pour d'autres il est sacrificiel, lié à un culte chthonien ou à une célébration collective indéterminée (voir supra, p. 119). Mais toutes ces hypothèses ont ceci de commun qu'elles supposent un rebouchage rapide du puits, immédiatement après l'accomplissement du rituel initial. Or, des données incontestables, fournies par l'archéozoologie et par l'étude du mobilier céramique, obligent à remettre cette idée en question.

La clé du problème était déjà présente dans la première publication sur les puits tolosates. Au fond du puits 4 de la Caserne Niel, L. Joulin avait trouvé des «élytres d'insectes » et un crâne de musaraigne à l'intérieur d'un pot (Joulin, 1912, p. 18 et tabl. h. t.). On sait aujourd'hui que les puits ouverts fonctionnent comme des pièges pour de nombreux insectes, notamment les coléoptères qui circulent activement à la surface du sol pendant la nuit (Kenward, 1975 ; Moret, 1998). En climat tempéré, l'exosquelette de ces coléoptères ne peut se conserver durablement qu'en milieu anaérobie, dans des terrains saturés d'eau en permanence. La découverte apparemment anodine de L. Joulin a donc deux implications capitales : elle prouve que le puits 4 atteignait la nappe phréatique, et qu'il resta ouvert un certain temps avant d'être rebouché. Il s'agissait donc, au moins dans une première phase, d'un puits à eau.

Curieusement, les éléments de cuticule d'insectes ne sont jamais cités dans les fouilles plus récentes, sans doute parce qu'ils n'ont pas été repérés et identifiés comme tels dans la masse des débris organiques. Mais d'autres restes d'animaux ont été recueillis qui fournissent des informations tout aussi précises, si ce n'est plus: les micromammifères et les batraciens. Les rapports d'analyse de faune signalent en effet des grenouilles (VT 4, 15 et 35), des pélobates (VT 4), des alytes ou crapauds accoucheurs (VT 4 et 14), des taupes (SR 13, VT 14), des mulots (SR 0, 10 et $14 ;$ VT 14), un lérot (VT 16), des campagnols (SR 13, 14 et 27 ; VT 14, 16 et 35 ) et des musaraignes (Joulin, 1912, puits 1 et 4). La plupart de ces découvertes sont isolées, faute le plus souvent d'un tamisage systématique des sédiments. Les résultats les plus éloquents ont été fournis par deux puits dont la microfaune, analysée par T. PoulainJosien, semble avoir fait l'objet d'une attention plus soutenue :

- puits 5 de Saint-Roch, au fond : 2 lézards, 8 grenouilles, 4 pélobates, 5 alytes, 1 lérot, 2 mulots, 1 campagnol souterrain ;

- puits 7 de Vieille-Toulouse: 152 microvertébrés, dont 42 grenouilles, 82 crapauds, 8 alytes, 1 hérisson et 19 micromammifères parmi lesquels des loirs, des campagnols roussâtres, des campagnols des champs, des mulots et des musaraignes.

J.-D. Vigne, qui a récemment étudié la question des assemblages de microvertébrés récoltés dans des structures excavées profondes (puits, fosses, silos), du Néolithique au Moyen Âge, a bien voulu nous faire part de ses observations sur le cas toulousain. Ces assemblages, caractérisés par la dominance des amphibiens et par une présence en quantité variable de micromammifères (notamment des soricidés), se forment par simple piégeage des animaux, tombés au hasard de leurs déplacements à la surface du sol. Le nombre particulièrement important d'amphibiens dans le puits 7 peut être lié à la présence d'eau stagnante. En tout état de cause, une intervention humaine (offrande funéraire selon Labrousse, 1968, p. 229) est exclue. On notera qu'à la même époque, on trouve des assemblages comparables dans des silos du village gaulois d'Acy-Romance dans les Ardennes (Lesur, 1999). Dans les deux cas, la conclusion est la même : le puits (ou le silo) est resté ouvert pendant une durée relativement longue, pouvant aller de quelques semaines à plusieurs années. On comprend mieux, dans ces conditions, pourquoi on a trouvé dans certains puits (VT 25, 26, 28) une couche de " marne bleue de décomposition » riche en 
matière organique. Cette vase, interprétée initialement comme un apport de sédiment extérieur (Vidal, 1977, p. 195), s'est tout simplement formée dans un puits ouvert au contact de l'eau stagnante.

Ajoutons une dernière observation, avant de risquer une tentative d'interprétation. Des seaux en bois ont été retrouvés dans les couches profondes de plusieurs puits (SR 2; VT 11, 16 et 26; Lectoure 8), parfois avec les crochets qui servaient à les suspendre à une corde (VT 11 et 16). Par ailleurs, il a été remarqué que les vases retrouvés entiers ou brisés sur place dans les mêmes couches profondes appartenaient pour près de $80 \%$ à des formes fermées de type « urne » (Vidal, 2001b, p. 124). Pour tous ces vases, le resserrement du col et l'épaississement du bord permettaient une suspension facile au moyen d'une corde nouée sous la lèvre. Précisément, des restes de corde ont été retrouvés encore en place autour du col de deux vases ovoïdes entiers, au fond de deux puits différents (Lectoure 8 et SR 5, cf. Vidal, 1976, p. 102). Il apparaît donc que la plupart des récipients retrouvés dans les niveaux profonds étaient adaptés au puisagc.

Nous voilà donc en présence de puits qui atteignaient la nappe phréatique, qui sont restés ouverts pendant une durée relativement longue, et dans lesquels on trouve fréquemment des seaux, des pots et des cruches permettant de puiser l'eau. Comment dès lors ne pas envisager d'identifier ces excavations profondes comme de simples puits à eau, au moins dans une des phases de leur utilisation?

Cette hypothèse n'a, curieusement, jamais été soutenue. M. Vidal l'évoque brièvement dans sa thèse, mais pour la réfuter. Tout en reconnaissant que la profondeur très variable des puits du Toulousain s'explique par la volonté systématique d'atteindre l'eau (Vidal, 1977, p. 286), il ne voit là qu'un souci religieux d'ordre symbolique. Deux motifs, selon lui, obligent à exclure la possibilité d'une fonction de puisage: le débit de l'eau phréatique serait trop faible à Vieille-Toulouse et l'absence de cuvelage, dans de nombreux puits, rendrait presque inévitable l'effondrement des parois à brève échéance, dans des terrains comportant des couches de sable intercalées (id., ibid., p. 305). La faiblesse du débit d'eau n'est pas un argument décisif, dans la mesure où M. Vidal fait lui-même état de hauteurs d'eau stabilisées de $1,50 \mathrm{~m}$ à $2 \mathrm{~m}$ dans les puits profonds à la fin de la fouille, ce qui suffisait amplement pour le puisage. Les difficultés rencontrées pour trouver une nappe d'eau pérenne peuvent d'ailleurs fort bien expliquer la multiplicité des creusements sur tout le site de Vieille-Toulouse ; on peut même supposer que des excavations ayant échoué à trouver l'eau furent ipso facto transformées en dépotoirs, ce qui expliquerait l'absence de dépôts profonds différenciés dans certains puits (VT 15, 30, 31, 44). Quant à l'absence de cuvelage, ce choix peut certes paraître peu rationnel, mais les faits sont là : les Tolosates préféraient apparemment creuser un nouveau puits dès que le précédent s'était obstrué, plutôt que de réaliser un cuvelage qui nécessitait une main-d'œuvre spécialisée et entraînait certainement un surcoût important.

Intéressons-nous maintenant aux couches de comblement. On a souvent insisté sur la présence massive des amphores dans le remplissage des puits toulousains, au point que s'est largement imposée l'idée que ces couches de comblement « à amphores ", censées s'être formées rapidement après le dépôt d'offrandes initial, étaient directement liées à un geste religieux ; plus précisément, on a supposé qu'elles représentaient les reliefs d'un banquet (en dernier lieu, voir Poux, 1999a, p. 130-132). Cette hypothèse n'a jamais été approfondie ni fondée sur une analyse prenant en compte la totalité des vestiges mis au jour par les fouilleurs.

Pourtant, un examen même rapide de l'ensemble des stratigraphies publiées fait apparaître une très grande diversité. Les amphores sont présentes en quantité variable, tantôt très abondantes (SR 13, 28 ; VT 20, 25, 44), tantôt peu nombreuses (SR 26, 29, 33 ; VT 15, 23, 24, 26), entières ou presque entières pour une bonne part (SR 0, 13, 27 ; VT 14, 18,44 ) ou à l'état de fragments (SR 14, 19, 30, 34; VT 19, $26,30)$. Il n'existe donc pas un faciès d'ensevelissement unique. D'autre part, $\mathrm{M}$. Vidal a rappelé à juste titre que le mobilicr dćposć intact dans les couches les plus profondes, selon des dispositifs concertés, contraste fortement avec le mobilier " fragmenté, incomplet et hétérogène " qui se trouve au-dessus dans les couches de comblement (Vidal, 2001b, p. 122 et 124). Pour aller plus loin dans l'interprétation, seule une analyse de l'ensemble des restes de vaisselle céramique présents dans ces couches supérieures peut permettre de savoir si l'on a affaire à un mobilier spécifique, lié à un usage particulier, ou au contraire s'il s'agit d'un matériel de rebut non sélectionné. Dans le premier cas, qui suppose une séquence creusement-dépôtcomblement sans hiatus, on s'attendrait à un faciès caractérisé par une faible fragmentation de la vaisselle et une surreprésentation de certaines catégories fonctionnelles (les vases à boire, par exemple). Dans le second cas, on s'attendrait à un mobilier plus fragmentaire et dont la répartition statistique serait proche de celle constatée dans les niveaux d'habitat. Il est donc indispensable, dans cette perspective, de comparer le faciès des couches de comblement des puits au faciès mobilier des habitats contemporains.

Dans l'analyse préliminaire que l'on propose ici, on a comparé le mobilier du puits 16 de Vieille-Toulouse, bien connu pour la richesse de son dépôt rituel initial, mais dont les niveaux de comblement ont moins retenu l'attention, au mobilier des niveaux les plus récents d'un secteur d'habitat 
situé juste à côté (habitat 5 ). Est aussi étudié le puits 5 de Saint-Roch, plus ancien, ce qui permet d'élargir quelque peu l'éventail chronologique.

\section{L'HABITAT 5 de VIEILle-Toulouse}

Les niveaux de l'habitat 5 de Vieille-Toulouse étudiés ici peuvent être datés entre les années 75 et 15 avant J.-C. Le mobilier céramique est fragmenté et hétérogène, une partie apparaissant comme probablement résiduelle (l'occupation de ce secteur d'habitat est attestée au moins depuis la fin du $\mathrm{II}^{\mathrm{e}}$ s.). Les campaniennes $\mathrm{B}$ de Calès dominent très largement les importations de céramiques fines (à peu près $9 \%$ du total des individus), suivies par les campaniennes $\mathrm{A}$ $(2,4 \%)$, caractéristiques des productions tardives. Les productions d'époque augustéenne (sigillées italiques à vernis noir ou rouge, présigillées sud-gauloises) sont nettement plus rares $(1,6 \%$ en tout). Au sein de ces quatre catégories dominent les assiettes (18 individus), les formes creuses étant plus rares. La vaisselle « de table " est cependant dominée par les productions indigènes dites " celtiques ", qu'il s'agisse des écuelles à bord rentrant (22 individus) ou des assiettes imitées des Lamboglia 36 (14 individus).

Les productions " celtiques " dominent très largement le faciès céramique, avec $43,1 \%$ des individus. La vaisselle de stockage est prédominante dans celte calégorie (40 individus), suivie des écuelles, des assiettes et d'autres types plus rares: jattes, imitations de prototypes méditerranéens divers... Les céramiques culinaires sont dominées par les pots à cuire montés à la main (à peu près 20,5\%), mais on constate aussi la présence de céramiques de type méditerranéen, communes italiques et à engobe rouge interne à hauteur d'environ $6 \%$. Sans être anecdotiques, les productions de céramiques à pâte claire sont rares $(3,6 \%)$ et dominées par les vases à verser. Plus rares encore sont les céramiques tournées à pâte sableuse et cuisson oxydante: seulement $1,6 \%$ du total. Les gobelets à parois minces, de formes diverses, représentent $3,6 \%$ du total. Un dolium représente la céramique de gros stockage, et on note la présence d'une petite cruche en céramique grise fine. Les lampes et les unguentaria sont représentés chacun par deux individus.

\section{LE PUITS 16 DE VIEILLE-ToulOUSE}

Initialement publié par M. Labrousse, M. Vidal et A. Muller (1976), le puits 16 a récemment fait l'objet d'une analyse qualitative prenant en compte l'ensemble du mobilier, dont nous retenons les conclusions chronologiques (Benquet et al., 2001, p. 133-134). Comme dans l'habitat 5 , le mobilier est fragmenté et hétérogène. Les vestiges les plus récents semblent remonter aux alentours de 15 avant J.-C. (fond d'assiette de céramique présigillée, bol arétin de Vibius Scrofula), alors que la majorité du matériel est attribuable au milieu du $I^{\text {er }}$ s. Toutes les classes de céramique déjà évoquées sont ici présentes, dans des proportions quasiment équivalentes à celles constatées dans l'habitat 5. Le faciès est dominé par les productions " celtiques " $(47,22 \%)$, au sein desquelles vaisselle « de table » et vaisselle de stockage se partagent cette fois-ci plus équitablement. Les écuelles à bord rentrant indigènes dominent très largement la vaisselle " de table " (46 individus), alors que la vaisselle fine importée (entre 11 et $12 \%$, en excluant les parois minces), dominée par les productions de campanienne $B$ de Calès, mais faisant une part plus large à la A que précédemment, fournit principalement des assiettes (13 individus). Les formes creuses, coupes et bols, sont également présentes. Les productions campaniennes - apparemment seulement les A - sont imitées en céramique "celtique ", au premier rang desquelles la Lamboglia 36 (8 individus). Les céramiques culinaires sont dominées par les pots montés à la main $(24,6 \%$ du total) ; le répertoire est complété par des importations, communes italiques et à engobe rouge interne (presque $6 \%$ du total), principalement des plats et leurs couvercles, mais aussi un pot. Les céramiques à pâte claire sont rares $(3,57 \%)$. Les gobelets à parois minces le sont un peu moins $(4,76 \%)$ et présentent une assez grande variété. Entre autres productions présentes de façon anecdotique (productions grises des côtes catalanes, céramique " celtique " à engobe blanc...), on peut noter la présence d'un unguentarium et d'un kalathos, peut-être d'imitation régionale. Un dolium évoque le gros stockage.

\section{LE PUITS 5 DE SAINT-Roch}

La stratigraphie de ce puits a été publiée par M. Vidal (1976). Ici aussi, le mobilier des couches de comblement est fragmenté. La domination des campaniennes A (13\% du total), ne portant pas d'estampilles et présentant parfois des cercles d'empilement sur le fond, ainsi que la présence d'une campanienne $B$ de Calès évoquent les années 125-100 avant J.-C. Les productions sont moins diversifiées que dans les deux autres cas (une caractéristique due à la chronologie), mais sont cependant assez variées. La table est dominée par les écuelles «celtiques », les apports extérieurs consistant cette fois-ci principalement en formes creuses. Les imitations indigènes de campaniennes sont rares. La céramique " celtique " domine avec près de $65 \%$ du total, et la catégorie est principalement consacrée au stockage. La céramique culinaire est rare: $5 \%$ des individus sont des pots indigènes montés à la main, et on note la présence 
précoce des céramiques communes italiques $(3,5 \%)$. Une cruche, un unguentarium, trois gobelets à parois minces et deux lampes à huile complètent le panorama des importations italiques. Les autres productions ne sont attestëes que par un individu: céramique ibérique peinte, céramique «celtique » peinte et céramique grise fine.

Les points communs qui unissent le mobilier issu de l'habitat 5 et celui de ces deux puits résident principalement dans la diversité des fonctions représentées, parmi lesquelles domine le stockage, et par le caractère fragmentaire du matériel. Les points communs sont évidemment plus nombreux avec le puits 16, plus proche chronologiquement (même si par plusieurs aspects son comblement donne l'impression d'être un peu plus ancien que le terminus ante quem envisagé pour l'habitat 5) : même aspect d'accumulation dans la durée donnant au lot son caractère hétérogène, présence de mobilier résiduel, catégories céramiques représentées de façon très frappante dans les mêmes proportions, proximité de la répartition fonctionnelle des vases. L'analyse du puits 5 , pourtant plus ancien, rćvc̀le un faciès relevant de la même logique : toutes les fonctions représentées dans le cadre domestique sont présentes, et le rapport statistique entre les diverses catégories est comparable à celui des deux autres ensembles étudiés, même si la répartition fonctionnelle évoluera au cours du $\mathrm{I}^{\mathrm{er}} \mathrm{s}$. avant J.-C. pour des raisons sur lesquelles on ne peut s'étendre ici.

Ainsi, le faciès de la vaisselle des couches de comblement de ces deux puits apparaît comme un reflet assez exact de celui issu des couches d'habitat. Si le caractère ponctuel de cette étude interdit de tirer des conclusions trop hâtives, il est cependant possible d'émettre avec force l'idée que les puits sont restés ouverts un certain temps et que leur comblement s'est fait principalement par des apports de terre et de déchets issus des secteurs d'habitat, - en clair, qu'il s'agissait de dépotoirs. Les modalités et la durée du processus de comblement sont certainement très variables d'un puits à l'autre. Dans les deux cas étudiés, il semble, d'après le mobilier, que cette durée ait été plus longue pour le puits 16 que pour le puits 5 . En tout état de cause, aucune intention rituelle n'est reconnaissable dans ces comblements, ce qui, dans le cas du puits 16 , contraste nettement avec le caractère manifestement préconçu et ordonné du dépôt initial.

En ce qui concerne les amphores, non prises en compte dans les analyses qui précèdent, on peut souligner que leur proportion est conforme à ce qui s'observe dans les habitats contemporains. Dans le puits 16, d'après les chiffres fournis par A. Hesnard et L. Benquet (in Benquet et al., 2001, p. 140), elles représentent $11,9 \%$ de l'ensemble des individus céramiques (34 sur 286). Cette proportion n'est sans doute pas la même dans tous les puits, mais elle permet de formuler l'hypothèse qu'il s'agit, comme pour le reste de la céramique, d'un matériel de rebut.

\section{Conclusion}

L'histoire de ces puits est à peu près la même que celle que J. Greig (1988) a mise en évidence pour des puits à eau d'époque romaine en Angleterre, en distinguant, selon les cas, deux ou trois phases bien différenciées (fig. 74).

1) Une période de fonctionnement pendant laquelle une sédimentation graduelle, produite essentiellement par l'érosion des parois, comble progressivement la partie inondée (dans certains cas, l'aspect homogène et stérile de ce sédiment a pu faire penser à un rebouchage immédiat après creusement). Le mobilier inclus est généralement peu varié, avec des récipients tombés ou cassés par suite de fausses manœuvres lors du puisage. Certains matériaux de rebut non polluants (tessons, pièces de bois) sont fréquemment jetés dans les puits pendant cette phase. Les éléments organiques et la microfaune deviennent plus abondants à la fin de cette période, par suite de la dégradation des structures.

2) Un niveau intermédiaire - parfois absent -, riche en débris organiques (mousses, feuilles, graines, noyaux, etc.), en tessons, en rejets alimentaires et en microfaune. Il correspond à une période d'abandon, quand l'cau a cessé d'être potable ou ne peut plus être puisée.

3) Un comblement définitif, en une fois ou en plusieurs temps, constitué par des apports variés d'ordures, de matériaux de rebut ou de simple terre. Il est important de noter que la prise en compte d'un intervalle de temps, pouvant aller jusqu'à plusieurs dizaines d'années entre le creusement et le comblement du puits, permet seule d'expliquer les écarts chronologiques qui sont parfois constatés entre le mobilier des dépôts profonds et celui des couches de remblaiement (dans le cas de VT 16, voir Benquet et al., 2001, p. 134).

On peut faire maintenant le compte des puits qui, d'après les données publiées, sont identifiables comme des puits à eau. Les critères de sélection sont au nombre de quatre: présence ininterrompue de l'eau dans la partie profonde du puits, facilement prouvée par la conservation des matières organiques; présence dans les niveaux profonds de microvertébrés et/ou d'insectes attestant une ouverture prolongée (la prise en compte de ce critère étant malheureusement impossible dans les puits où la microfaune n'a pas été prélevée); présence d'instruments de puisage (seaux, pots susceptibles d'être attachés à une corde, crochets) ; caractère hétérogène et détritique des couches de comblement. 


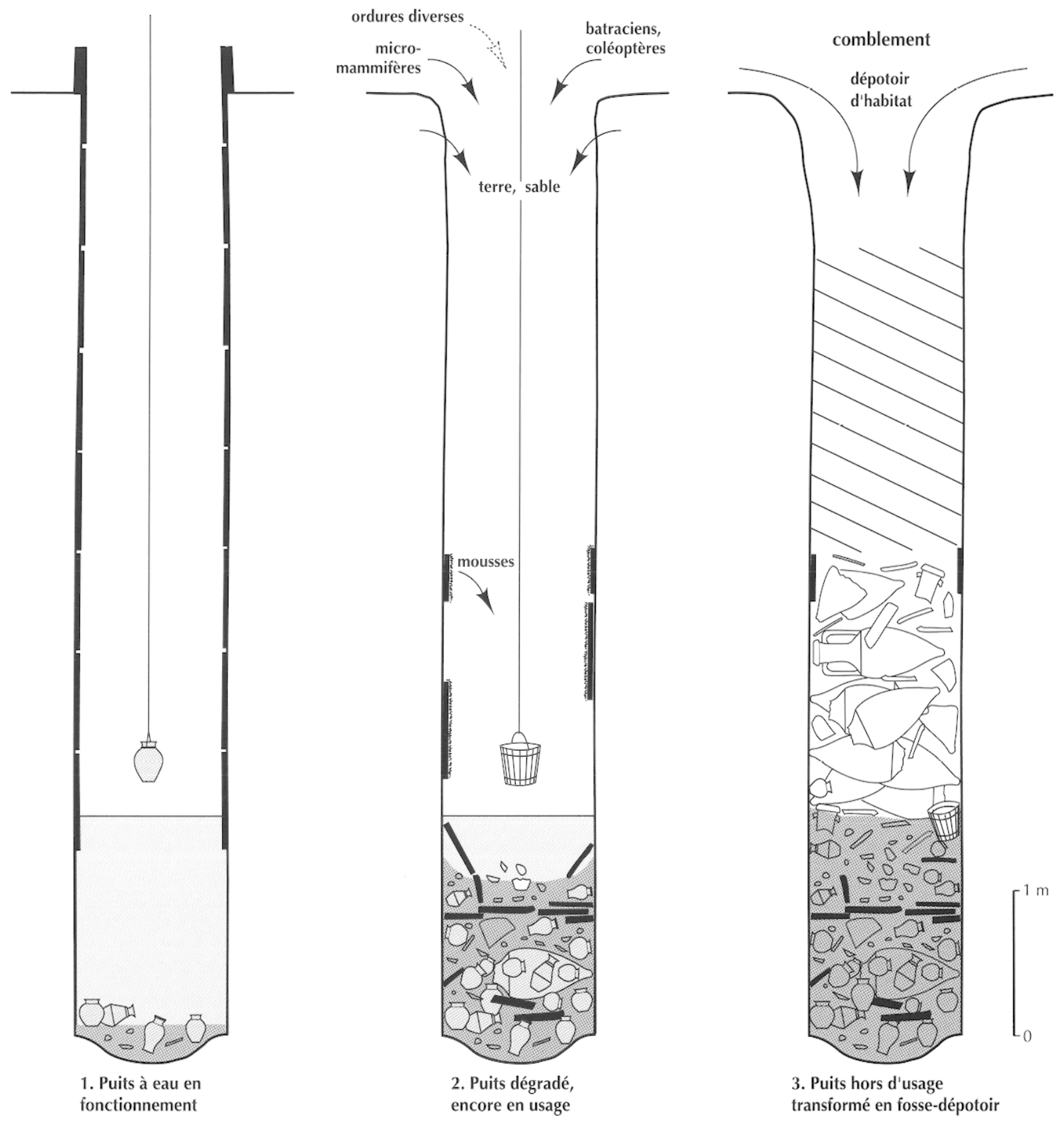

Fig. 74 - Proposition de restitution des phases de comblement d'un puits du quartier Saint-Roch à Toulouse, à partir de la stratigraphie du puits 5 (d'après Vidal, 1976, fig. 2 modifiée).

Un examen rapide des données synthétisées par M. Vidal (1977) donne comme résultat la liste provisoire suivante, arrêtée à l'année 1976: puits 2, 5, 13 et 25 de Saint-Roch (auxquels peuvent être ajoutés les puits 4, 32, 96, 118 et 121 de L. Joulin, décrits par cet auteur comme "inondés ") ; puits $2,7,11,13,16,25,26,28,31,33$ et 35 de VieilleToulouse ; puits 3 de Bazièges ; puits 8 de Lectoure ; puits 1 de Vic-Fezensac. D'autres puits, qui renfermaient des réci- pients caractéristiques et des microvertébrés, n'ont pas conservé de restes végétaux (par exemple VT 4, 14, 23). Il peut s'agir de puits à eau qui se sont asséchés par la suite, soit pendant la période d'occupation du site, soit à une date plus récente.

Jusqu'à ce point de l'analyse, nous avons fait abstraction des dépôts organisés, évidemment intentionnels et parfois très riches, qui existent au plus profond de certains puits. Le 
cas le plus connu est celui du puits 16 de Vieille-Toulouse, déjà cité ; en revanche, d'après notre restitution, le puits 5 de Saint-Roch en était dépourvu. Comment expliquer ces dépôts si l'on a affaire à des puits à eau ? Les données stratigraphiques montrent sans ambiguité que les offrandes ont été déposées peu de temps après le creusement du puits et avant sa mise en service, puisqu'elles sont souvent scellées par une chape de marne ou de sable, et parfois protégées par des planches (Vidal, 2001b, p. 124). Il s'agit donc, selon toute probabilité, d'un sacrifice propitiatoire offert par le propriétaire du puits (s'il était privé, cf. Gorgues, à paraître) ou par l'autorité édilitaire (s'il était public) à une divinité souterraine, peut-être une divinité censée régir les eaux phréatiques.

Une interprétation plus précise de ces dépôts serait illusoire, en l'état du dossier, compte tenu de la diversité des dispositifs. Ceux-ci regroupent en effet un nombre d'objets très variable (un au minimum, plus d'une dizaine au maximum, entiers ou fragmentaires), sur un plan ou sur plusieurs plans superposés, placés tantôt de façon aléatoire, tantôt selon des schémas apparemment géométriques (Vidal, 1977; Gomez de Soto, 1994). Il y a cependant une constante dans la nature des objets déposés entiers. Ce sont presque tous des récipients : pots, cruches, situles ou seaux; aucun n'était bouché ou fermé par un couvercle. Les conditions des fouilles n'ont pas permis de savoir s'ils étaient vides au moment du dépôt. S'agissant d'instruments pouvant servir à recueillir l'eau - ou de leurs substituts précieux que sont la situle, la cruche en bronze et le seau à cerclage de bronze orné -, on pourrait envisager, à titre d'hypothèse, qu'ils firent l'objet d'un sacrifice en tant que récipients, et non pour leur éventuel contenu. On tendrait alors à établir un lien symbolique direct entre l'acte rituel initial et la fonction de puits à eau. Mais certains dépôts (très rares, il est vrai) contiennent aussi des armes, ce qui suppose des intentions plus complexes. Il existe aussi, dans quelques puits, plusieurs dépôts d'offrandes à des niveaux différents, ce qui implique une répétition périodique du rituel (à titre purement comparatif, on rappellera qu'à Rome des sacrifices périodiques étaient rendus à la déesse des eaux souterraines, le jour des Fontinalia, cf. Dumézil, 1975, p. 37). Il reste donc beaucoup à faire pour élucider la signification de ces dépôts profonds. En tout état de cause, leur présence régulière dans des puits qui furent ensuite utilisés pour l'eau est une donnée fondamentale.

Pour conclure, nous voudrions insister sur deux points. En premier lieu, l'interprétation que nous proposons n'est nullement exclusive. Elle ne vaut pas pour tous les puits du Toulousain; une analyse détaillée du corpus, cas par cas, devra préciser la part réelle qui revient parmi eux aux puits à eau. Il ne s'agit donc pas, dans notre esprit, de remplacer terme à terme une théorie par une autre ; tout au contraire, notre but est de mieux rendre compte de la diversité des données archéologiques. En second lieu, il n'est pas question de minimiser l'importance des pratiques cultuelles dans l'utilisation de ces puits. Loin d'être évacué, le rituel nous semble, au contraire, susceptible d'être mieux cerné et compris dès lors que l'on définit clairement sa place dans l'une des phases de l'histoire des puits. En ce sens, nous sommes assez proches des positions récemment exprimées par G. Wieland, qui tout en réinterprétant comme des puits à eau les puits des Viereckschanzen de Holzhausen, Tomerdingen et Fellbach-Schmiden, admet la signification cultuelle de certains dépôts bien caractérisés (Wieland $e t$ al., 1999, p. 4453).

Bibliographie : Joulin, 1912 ; Labrousse, 1968 ; Labrousse et al., 1976 ; Vidal, 1976, 1977, 1989, 2001b ; Kenward, 1975 ; Greig, 1988; Gomez de Soto, 1994 ; Moret, 1998 ; Lesur, 1999 ; Poux, 1999a ; Wieland et al., 1999 ; Benquet et al., 2001 ; Gorgues, à paraître.

A. Gorgues et P. MORET 